\title{
The World Health Organization Classification of Odontogenic Lesions: A Summary of the Changes of the 2017 ( $\left.4^{\text {th }}\right)$ Edition
}

\author{
Merva SOLUK-TEKKEŞIN' ${ }^{1}$, John M. WRIGHT² \\ 'Department of Tumor Pathology, Institute of Oncology, Istanbul University, ISTANBUL, TURKEY, \\ ${ }^{2}$ Department of Diagnostic Sciences, School of Dentistry, Texas A\&M University, DALLAS, TX, USA
}

\begin{abstract}
The $4^{\text {th }}$ edition of the World Health Organization (WHO) Classification of Head and Neck Tumors was published in January 2017. The edition serves to provide an updated classification scheme, and extended genetic and molecular data that are useful as diagnostic tools for the lesions of the head and neck region. This review focuses on the most current update of odontogenic cysts and tumors based on the $2017 \mathrm{WHO}$ edition. The updated classification has some important differences from the $3^{\text {rd }}$ edition (2005), including a new classification of odontogenic cysts, 'reclassified' odontogenic tumors, and some new entities.
\end{abstract}

Key Words: WHO classification, Odontogenic cysts, Odontogenic tumors, Update, Odontogenic keratocyst

\section{INTRODUCTION}

The World Health Organization (WHO) series on histologic and genetic typing of human tumors are generally updated approximately every 10 years for nearly all organ systems. These reference books provide updated tumor classification schemes based on currently available data, diagnostic criteria, as well as an international standard for professionals. The WHO $4^{\text {th }}$ edition of Head and Neck Tumors was published in January 2017 and it is the ninth volume in the $4^{\text {th }}$ edition of the WHO series (1). The publication of this edition followed the meeting of an expert consensus group that met in Lyon, France January 13-16, 2016. The participants the WHO invited on the Consensus and Editorial Panel included Prof Takashi Takata, Japan, Chair; Prof Daniel Baumhoer, Switzerland; Prof Samir El-Mofty, United States of America (USA); Prof Edward Odell, United Kingdom (UK); Prof Paul Speight, UK; Prof John Wright, USA, Prof Rosnah Zain, Malaysia (2). In the field of odontogenic tumors and cysts, this consensus work is critical given the reincorporation of odontogenic cysts, reclassified tumors, new entities, and current rapid rate of discovery of genetic and molecular alterations. The working group debated and edited each tumor/cyst in detail, and reviewed both historical and current evidence of each entity in the literature in order to provide a consensus text on all entities. Major objectives of the panel were 1. Simplicity, 2. Reproducibility, 3. Scientific accuracy, and 4. Utility for the practicing community of surgical pathologists.

Received : 04.07.2017 Accepted : 13.07.2017
The 2017 edition, like earlier editions, mainly divided odontogenic tumors into two categories, based on biologic behavior as malignant and benign. However, the 2005 classification organized benign odontogenic tumors as 'Odontogenic epithelium with mature, fibrous stroma without odontogenic ectomesenchyme,' 'Odontogenic epithelium with odontogenic ectomesenchyme, with or without hard tissue formation,' and 'Mesenchyme and/or odontogenic ectomesenchyme with or without odontogenic epithelium' (3), whereas the 2017 edition includes a simpler format such as epithelial, mesenchymal (ectomesenchymal), and mixed odontogenic tumors. The complex and detailed malignant odontogenic tumor classification of the 2005 edition was also made simpler by this new classification. Another very important change of the new edition is to have an odontogenic cyst classification that was eliminated from the 2005 edition. The last effective WHO odontogenic cyst scheme was published in 1992. Therefore, the odontogenic cyst classification has been significantly updated since 1992 . Table I summarizes the current odontogenic tumor and cyst classification (1).

The aim of this review is to discuss updates in the new 2017 WHO odontogenic lesions classification, outlining changes from the 2005 WHO classification, with emphasis on newly described and reclassified entities and illustrate the salient pathologic features of this diverse group of cysts and neoplasms.

Correspondence: Merva SOLUK-TEKKEŞiN

Department of Tumor Pathology, Institute of Oncology, Istanbul University, İSTANBUL, TURKEY

E-mail: msoluk@istanbul.edu.tr Phone: +90 5327487057 
Table I: 2017 WHO classification of odontogenic tumors and cysts

\begin{tabular}{l}
\hline Malignant Odontogenic Tumors \\
\hline Ameloblastic carcinoma \\
Primary intraosseous carcinoma, NOS \\
Sclerosing odontogenic carcinoma \\
Clear cell odontogenic carcinoma \\
Ghost cell odontogenic carcinoma \\
Odontogenic carcinosarcoma \\
Odontogenic sarcomas
\end{tabular}

\begin{tabular}{l} 
Benign Odontogenic Tumors \\
\hline Epithelial Origin \\
Ameloblastoma, conventional \\
$\quad$ Ameloblastoma, unicystic type \\
$\quad$ Ameloblastoma, extraosseous/ peripheral type \\
$\quad$ Metastasizing (malignant) ameloblastoma \\
Squamous odontogenic tumor \\
Calcifying epithelial odontogenic tumor \\
Adenomatoid odontogenic tumor \\
Mixed (Epithelial-Mesenchymal) Origin \\
Ameloblastic fibroma \\
Primordial odontogenic tumor \\
Odontoma \\
$\quad$ Compound type \\
$\quad$ Complex type \\
Dentinogenic ghost cell tumor \\
Mesenchymal Origin \\
Odontogenic fibroma \\
Odontogenic myxoma/myxofibroma \\
Cementoblastoma \\
Cemento-ossifying fibroma
\end{tabular}

\section{Odontogenic Cysts}

Developmental Origin

Dentigerous cyst

Odontogenic keratocyst

Lateral periodontal and botryoid odontogenic cyst

Gingival cyst

Glandular odontogenic cyst

Calcifying odontogenic cyst

Orthokeratinized odontogenic cyst

\section{Inflammatory Origin}

Radicular cyst

Collateral inflammatory cyst

\section{MALIGNANT ODONTOGENIC TUMORS}

- Ameloblastic carcinoma

- Primary intraosseous carcinoma

- Sclerosing odontogenic carcinoma

- Clear cell odontogenic carcinoma

- Ghost cell odontogenic carcinoma

- Odontogenic carcinosarcoma

- Odontogenic sarcomas

This section includes numerous updates from the 2005 edition, including simple reclassification of ameloblastic carcinoma and primary intraosseous carcinoma, the addition of the new entity of sclerosing odontogenic carcinoma, reconstituting the entity carcinosarcoma, odontogenic sarcomas without subclassification, and excluding metastasizing ameloblastoma, which was subclassified under the ameloblastoma group because of its bland histologic features. While a majority of the panel agreed to move metastasizing ameloblastoma from malignant to benign, this decision was not unanimous.

In the 2005 classification, ameloblastic carcinomas were divided into three categories; primary type (a), secondary type (dedifferentiated) intraosseous (b) and secondary type (dedifferentiated), peripheral (c). These tumors are now classified under 'ameloblastic carcinoma' based on the morphologic continuum and similar behavior between these entities. Ameloblastic carcinoma is a malignant counterpart of ameloblastoma and also shares the same BRAF mutation (4). In addition to the classic malignant features of ameloblastic carcinoma, this tumor expresses SOX2 and has a higher Ki-67 proliferation index than its benign counterpart, ameloblastoma (5-7) (Figures 1 A,B).

Like ameloblastic carcinomas, the primary intraosseous carcinomas (PIOC) category was also narrowed and became a single entity. It had previously been divided into three different categories based on their histogenesis in 2005. PIOCs arise from odontogenic epithelium with no precursor lesion or arise from odontogenic cyst epithelium or other benign precursors. One hundred sixteen welldocumented PIOC cases arising from odontogenic cysts have been published over the past 70 years starting from 1938. The most common precursor odontogenic cysts are radicular/residual cysts, followed by dentigerous and odontogenic keratocysts (8) (Figure 2). Seventy-seven additional PIOC cases were published with prognostic factors in 2016 by a single institute (9). When pathologists are faced with PIOC, metastatic lesions, other malignant odontogenic and intraosseous salivary gland tumors, and carcinomas of other anatomic structures should be included 

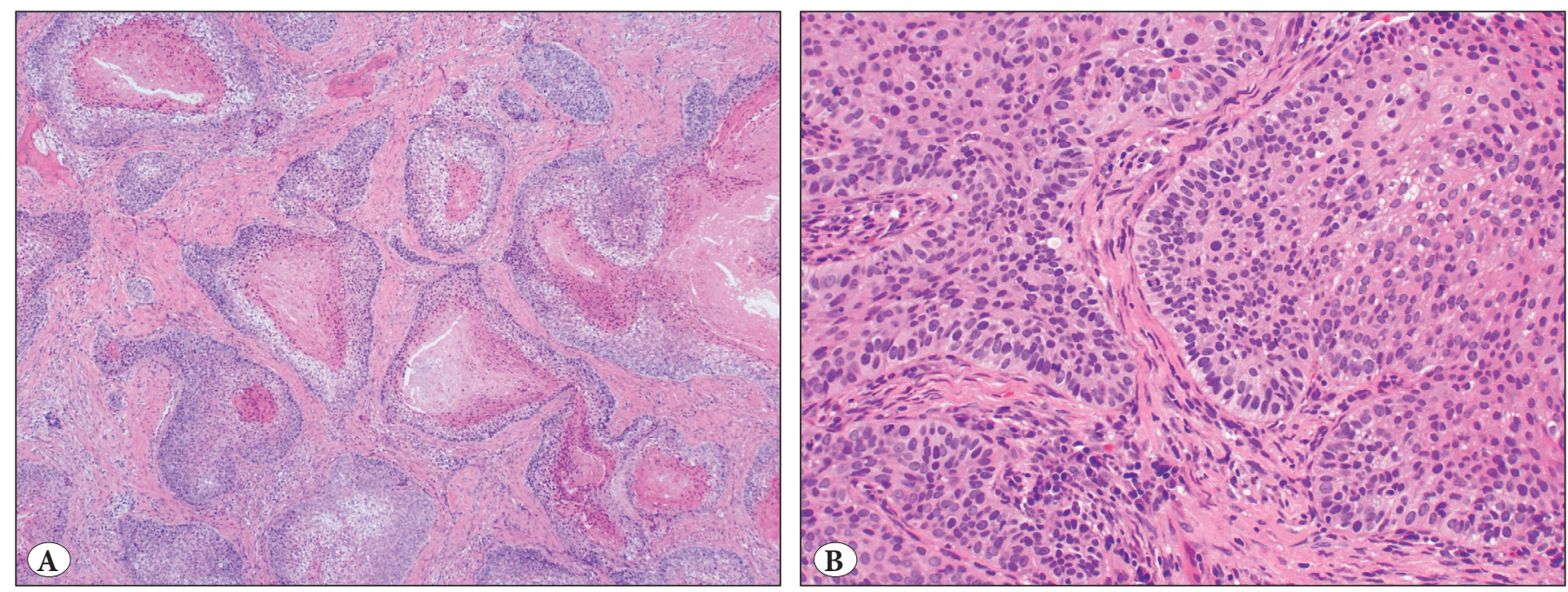

Figure 1: A) Ameloblastic carcinoma. Islands of cytologically atypical epithelium with central necrosis or keratinization (H\&E; x100). B) Ameloblastic carcinoma demonstrating palisading of the peripheral cells with reverse nuclear polarization. Oftentimes with malignancy, this feature is only minimally retained (H\&E; $\mathrm{x} 200)$.

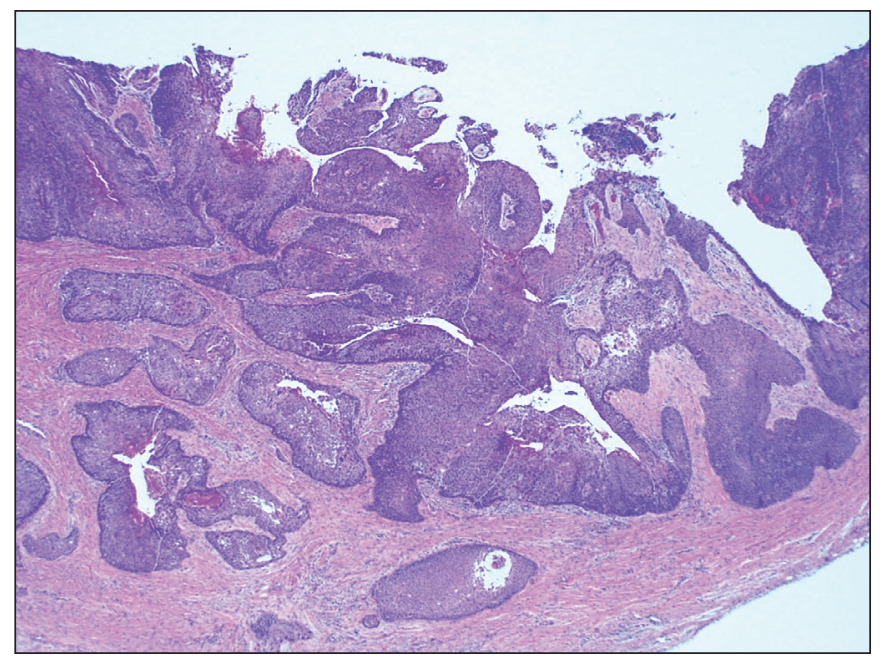

Figure 2: Primary intraosseous odontogenic carcinoma arising in an apical periodontal cyst (H\&E; $x 40)$.

in the differential diagnosis. By default, once these other possibilities have been ruled out, any malignant epithelial tumor in the jaws is PIOC (Figure 3). Odontogenic carcinomas, including ameloblastic carcinomas can rarely show transition to malignant spindle cell proliferations. In such cases, the diagnosis should be sarcomatoid or spindle cell odontogenic carcinoma rather than odontogenic carcinosarcoma $(1,10,11)$.

Sclerosing odontogenic carcinoma was first described in 2008 (12). In the 2017 classification it was introduced as a primary intraosseous carcinoma of the jaw, which has densely sclerotic stroma, bland cytology, and aggressive infiltration. To date, about 10 cases have been reported (1, 2). The tumor is characterized by small single-file cords

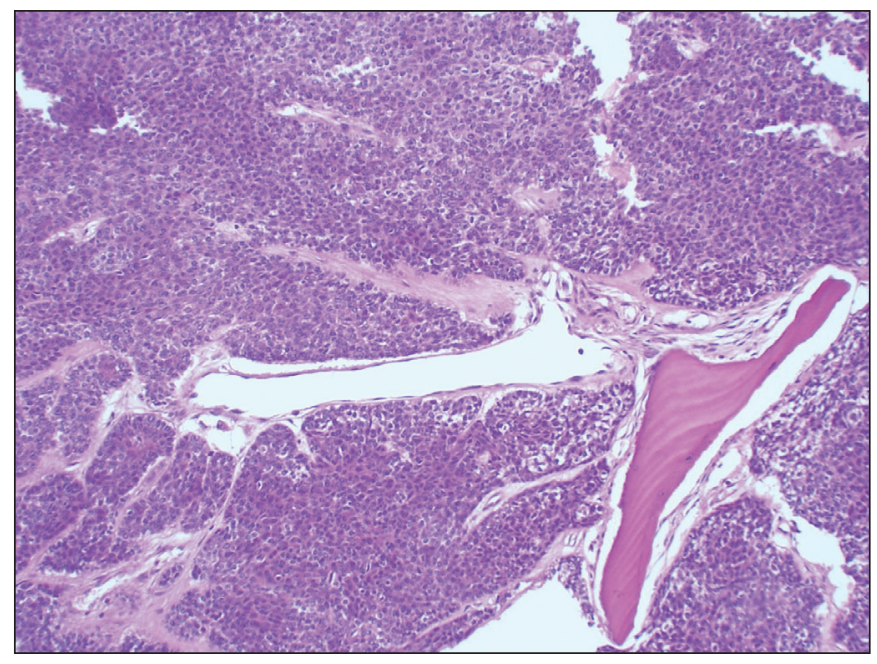

Figure 3: Primary intraosseous carcinoma with hypercellularity, cytologic atypia and mitoses (H\&E; x100).

and strands of epithelium in a markedly dense stroma. The epithelial component can be conspicuous and highlighted using immunohistochemical staining including CK19, CK5/6, p63 positivity, and focal and subtle positivity of CK7 (12-14) (Figures 4A,B). However, the cytologic features are bland, and invasion of skeletal muscle and nerve is characteristic. Pathologists should keep this tumor in mind because it is a new entity, and also exclude the diagnosis of metastasis, epithelium-rich central odontogenic fibroma, desmoplastic ameloblastoma, calcifying epithelial odontogenic tumor, and clear cell odontogenic carcinoma before making this diagnosis. The main treatment is resection. To date, only one case recurred after initial curettage (13) and no metastases have yet been reported. 

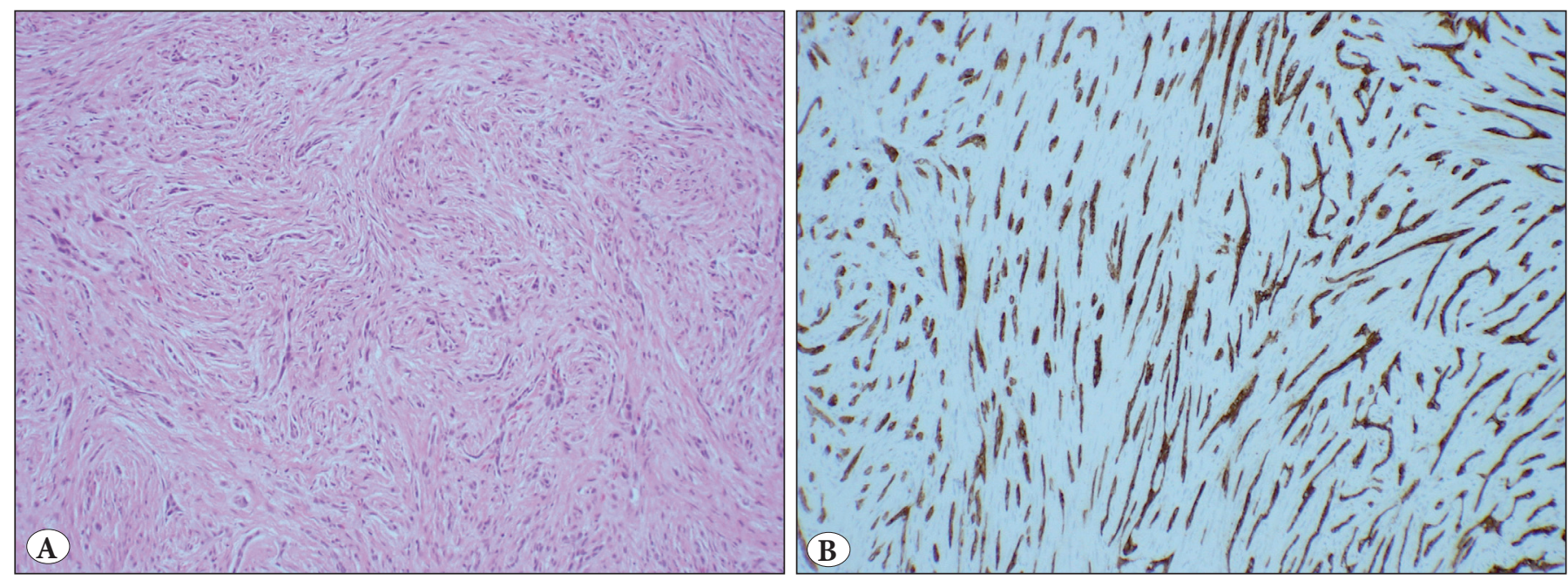

Figure 4: A) Sclerosing odontogenic carcinoma with thin strands of cytologically bland epithelium. The epithelial component can be deceptive on H\&E staining (H\&E; x100). B) Sclerosing odontogenic carcinoma (Cytokeratin IHC; x200).

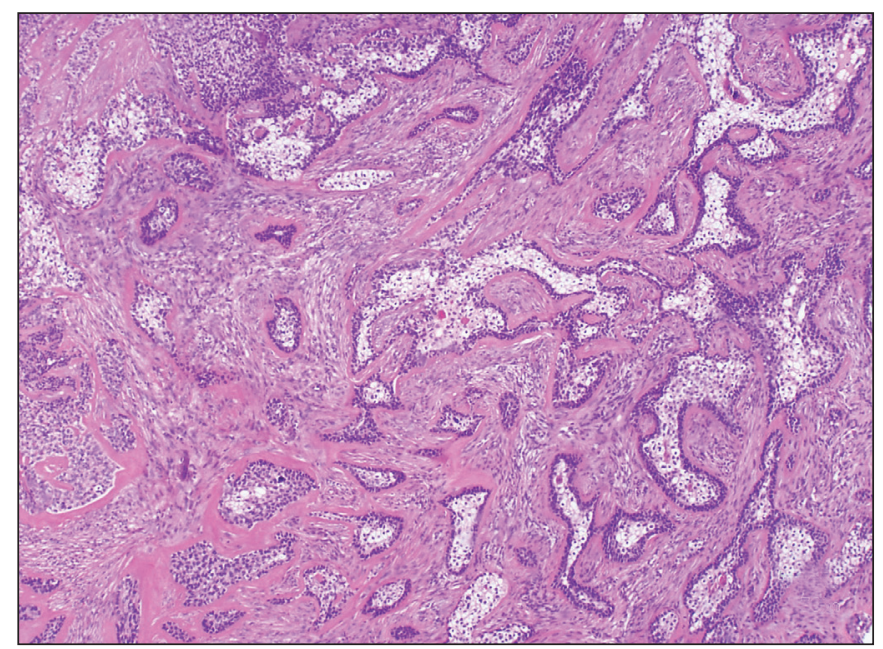

Figure 5: Clear cell odontogenic carcinoma. Epithelial neoplasm with significant clear cell change. Metastatic disease must always be ruled out (H\&E; $\mathrm{x} 100)$.

This tumor needs genetic or molecular characterization to fortify it being a separate entity from other carcinomas.

No major changes were made in clear cell odontogenic carcinomas and ghost cell odontogenic carcinomas, but additional genetic and molecular data are now available. Most clear cell odontogenic carcinomas have shown rearrangements of EWSR1 in which some researchers confirmed ATF1 to be the fusion partner $(15,16)$. The same translocation has long been known for hyalinizing clear cell carcinoma of the salivary glands (17). These two tumors also share similar immunohistochemical profiles (18). With all these similarities, the question remains as to whether these lesions are related. We think that the answer will be revealed before the next classification. Clear cell morphology in tumors are always challenging because they

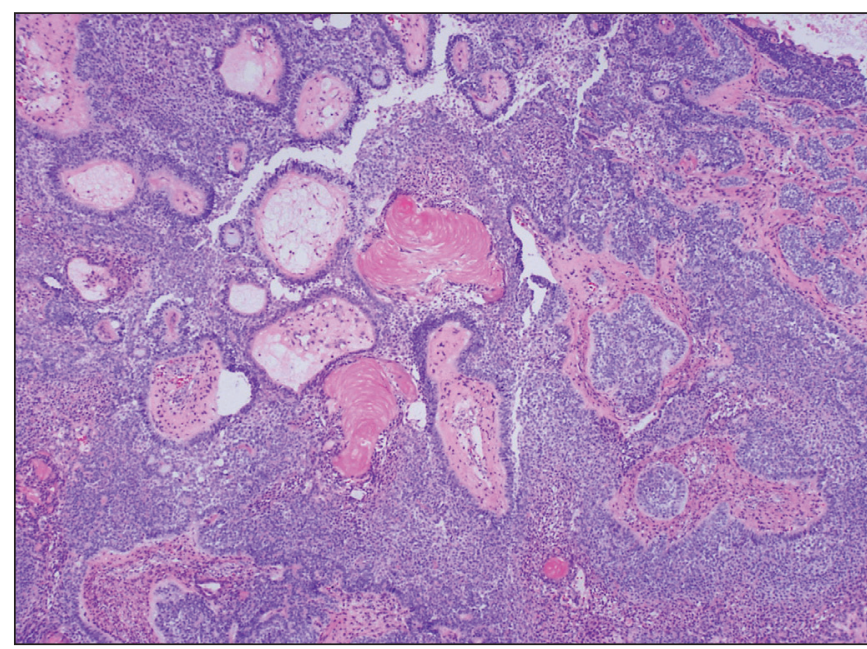

Figure 6: Ghost cell odontogenic carcinoma. The diagnosis requires cytologic atypia, mitoses and ghost cells (H\&E; x100).

share many similar features (Figure 5). Metastatic renal cell carcinoma, melanoma, and intraosseous mucoepidermoid carcinoma with prominent clear cells should be kept in mind as a priority when considering clear cell malignancy. The old synonyms of 'clear cell odontogenic tumor' and 'clear cell ameloblastoma' were made obsolete.

Ghost cell odontogenic carcinoma (GCOC) is an extremely rare tumor of ghost cells. An international collaborative study group on ghost cell odontogenic tumors gathered and discussed all ghost cell lesions (19). Of the 122 cases discussed, only 3 were GCOC. GCOCs are a malignant counterpart of calcifying odontogenic cyst (COC) or dentinogenic ghost cell tumor (DGCT). GCOCs require cytologic evidence of malignancy (Figure 6). p53 expression and a high proliferation index are key aspects for a diagnosis 


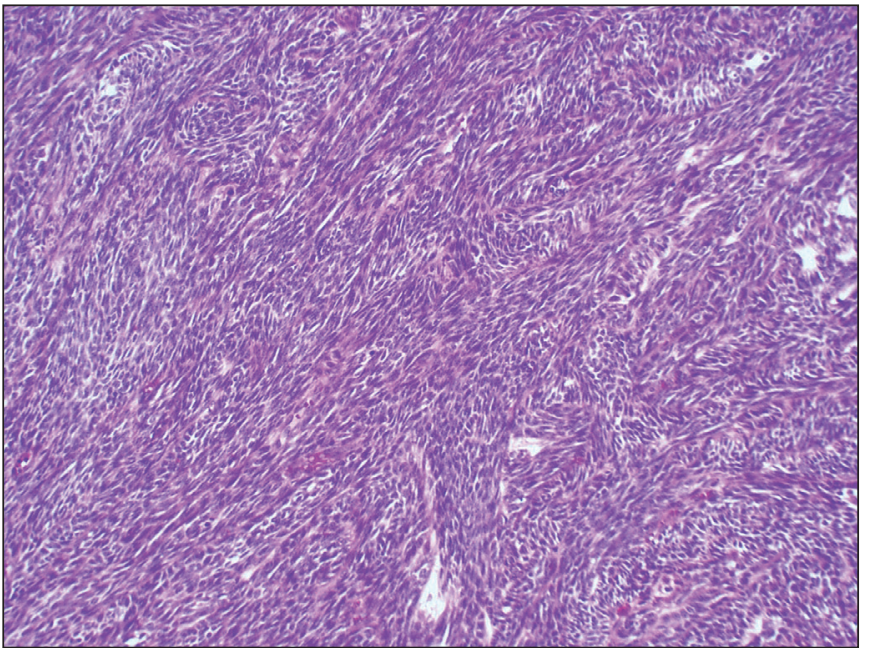

Figure 7: Odontogenic carcinosarcomas. The epithelial and mesenchymal components show cytologic features of malignancy. Consideration must be given to the possibility that the spindle cell component is epithelial (H\&E; x100).

of GCOC versus DGCT in the 2017 edition (20). There are limited studies on molecular aspects because of the rarity of the tumor. In the new edition, a single case has been documented with a distinctive molecular profile, multiple changes in the SHH signaling pathway, and a novel APC mutation (21).

Odontogenic carcinosarcoma was added in the $1992 \mathrm{WHO}$ malignant odontogenic tumors classification and then eliminated from the 2005 classification because most of the cases published were prior to IHC and current diagnostic criteria. Odontogenic carcinosarcoma has been accepted again in 2017 edition because of cases with adequate immunohistochemical and/or molecular support $(22,23)$ (Figure 7).

Previously, in 2005, odontogenic sarcomas were classified as ameloblastic fibrosarcoma and ameloblastic fibrodentinosarcoma and ameloblastic fibro-odontosarcoma depending on whether and what dental hard tissues were formed (Figures $8 \mathrm{~A}, \mathrm{~B}$ ). Now, these malignant tumors are collected under the umbrella of odontogenic sarcomas and it has been clarified that most common type is ameloblastic fibrosarcoma, which is the malignant counterpart of ameloblastic fibroma (24). Most of the odontogenic sarcomas are between low and intermediate grade. Anaplastic type has also been reported and alterations of the p53 and c-KIT genes restricted to the sarcomatous component have been observed in this type of ameloblastic fibrosarcoma (25).
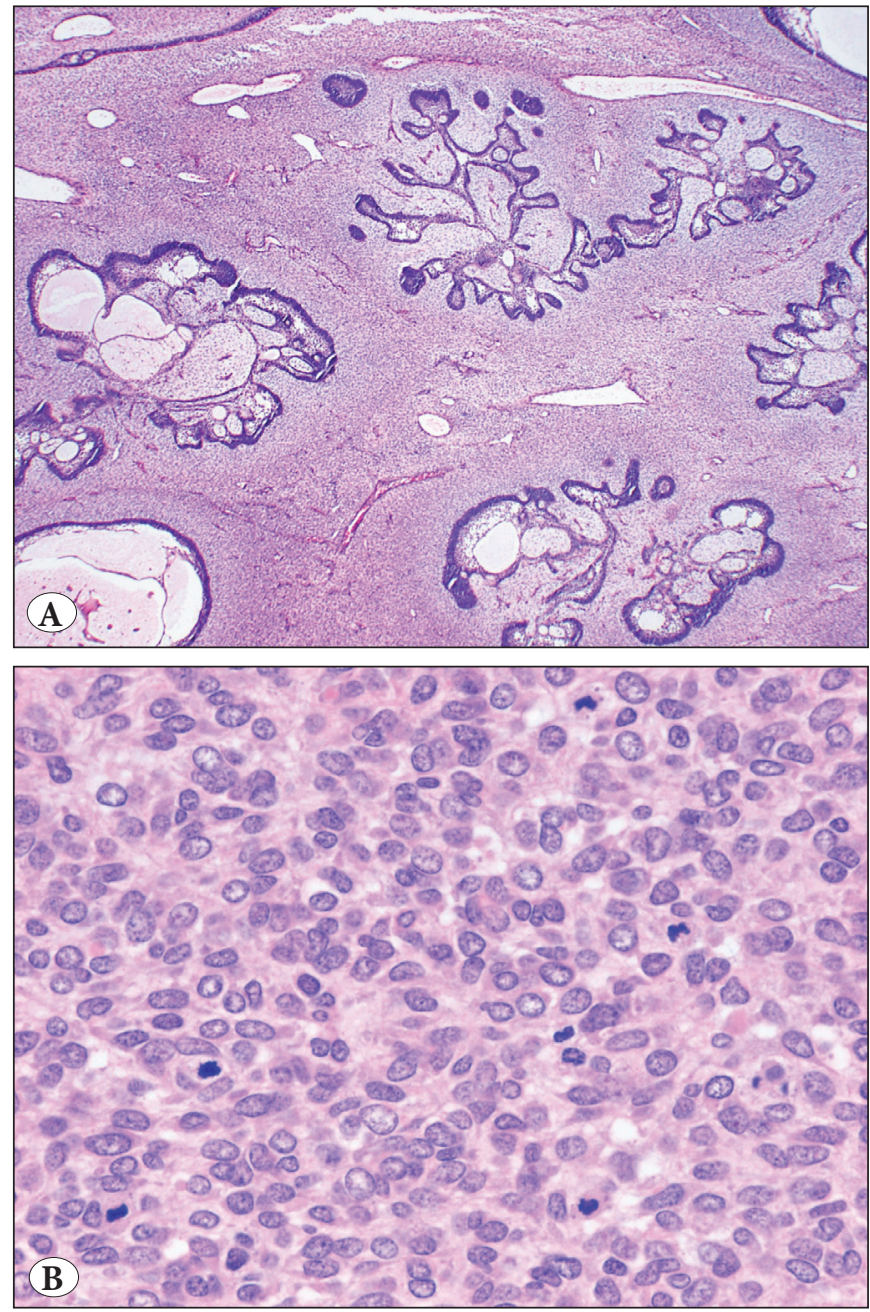

Figure 8: A) Odontogenic sarcoma. Specifically ameloblastic fibrosarcoma since no dental hard tissues are formed. The epithelial component is benign, the mesenchymal component shows hypercellularity, increased mitoses and cytologic atypia (H\&E; x40). B) Odontogenic sarcoma. Note hypercellularity, cytologic atypia and mitoses (H\&E; x400).

\section{BENIGN ODONTOGENIC TUMORS, EPITHELIAL}

- Ameloblastoma, conventional

- Ameloblastoma, unicystic type

- Ameloblastoma, extraosseous/ peripheral type

- Metastasizing (malignant) ameloblastoma

- Squamous odontogenic tumor

- Calcifying epithelial odontogenic tumor

- Adenomatoid odontogenic tumor

The most notable change in this tumor group is that keratocystic odontogenic tumors of 2005 are now classified under developmental odontogenic cysts under the name of odontogenic keratocysts (see odontogenic cyst section). 
Another major change in this group is the update of ameloblastoma types based on current genetic studies. Ameloblastomas were classified as solid/multicystic, extraosseous/peripheral, desmoplastic, and unicystic types in the 2005 classification. The 2017 classification has been narrowed to ameloblastoma, unicystic ameloblastoma, and extraosseous/peripheral types. The term solid/multicystic was dropped because most conventional ameloblastomas show cystic degeneration with no biologic differences. The desmoplastic type was left under the histopathologic subtype instead of becoming a separate entity because ameloblastomas have different histopathologic types, including follicular, plexiform, acanthomatous, granular cell, basaloid, and desmoplastic. Follicular is the most common and diagnostic pattern where the central areas of the neoplastic islands are loose and resemble the stellate reticulum of the developing tooth germ and the peripheral cells are columnar (palisaded) and display reverse nuclear polarity (Figures 9A,B). Plexiform is characterized by thin lamina like strands but there are two distinct patterns. One where the cells are basaloid and often arranged in a double row of basaloid cells without peripheral palisading or reverse nuclear polarity. In the second pattern of plexiform, the cords are thicker, the central cells more squamous but without peripheral palisading or reverse nuclear polarity (Figures 10A,B). The acanthomatous
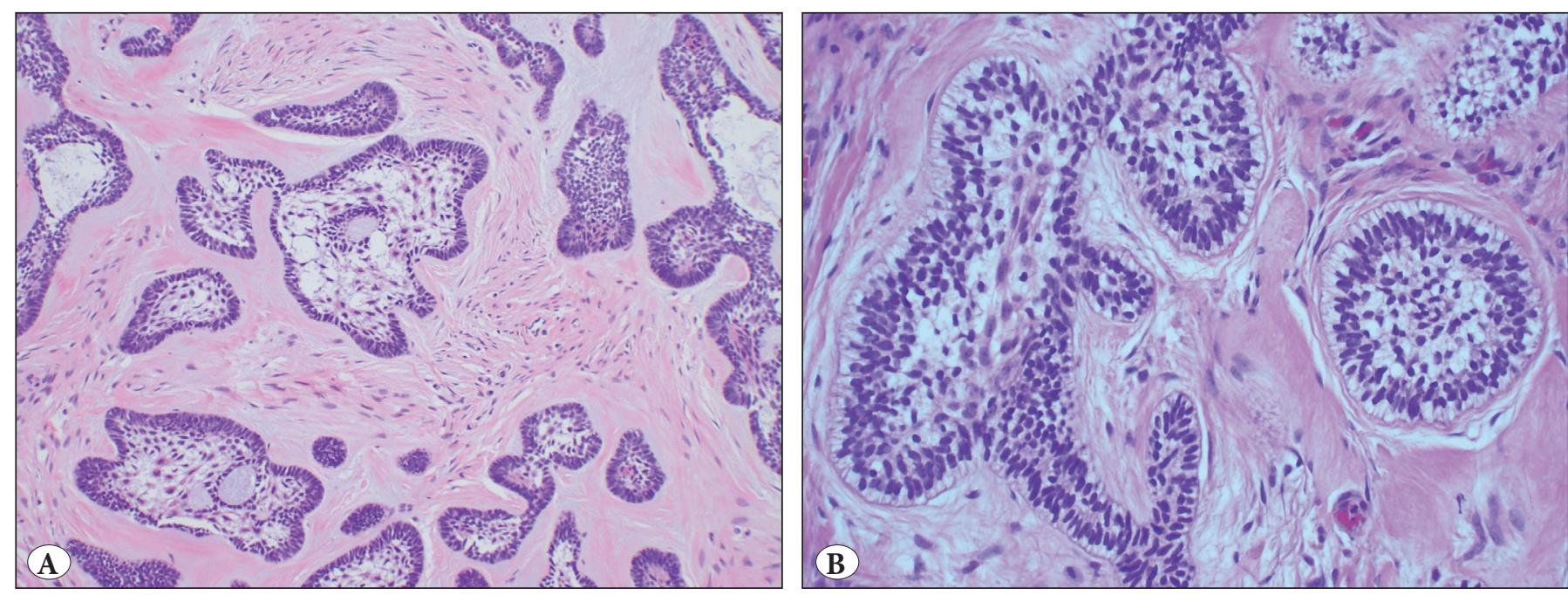

Figure 9: A) Follicular ameloblastoma. Islands of epithelium with central loosening of short spindled epithelial cells with peripheral palisading and reverse nuclear polarity (H\&E; x200). B) Follicular ameloblastoma. Diagnostic feature of peripheral palisading (columnar morphology) with reverse nuclear polarity (normal ameloblast nuclei are on the basement membrane but have to move to the other pole of the cell when they secrete enamel matrix proteins) (H\&E; $\mathrm{x} 400)$.
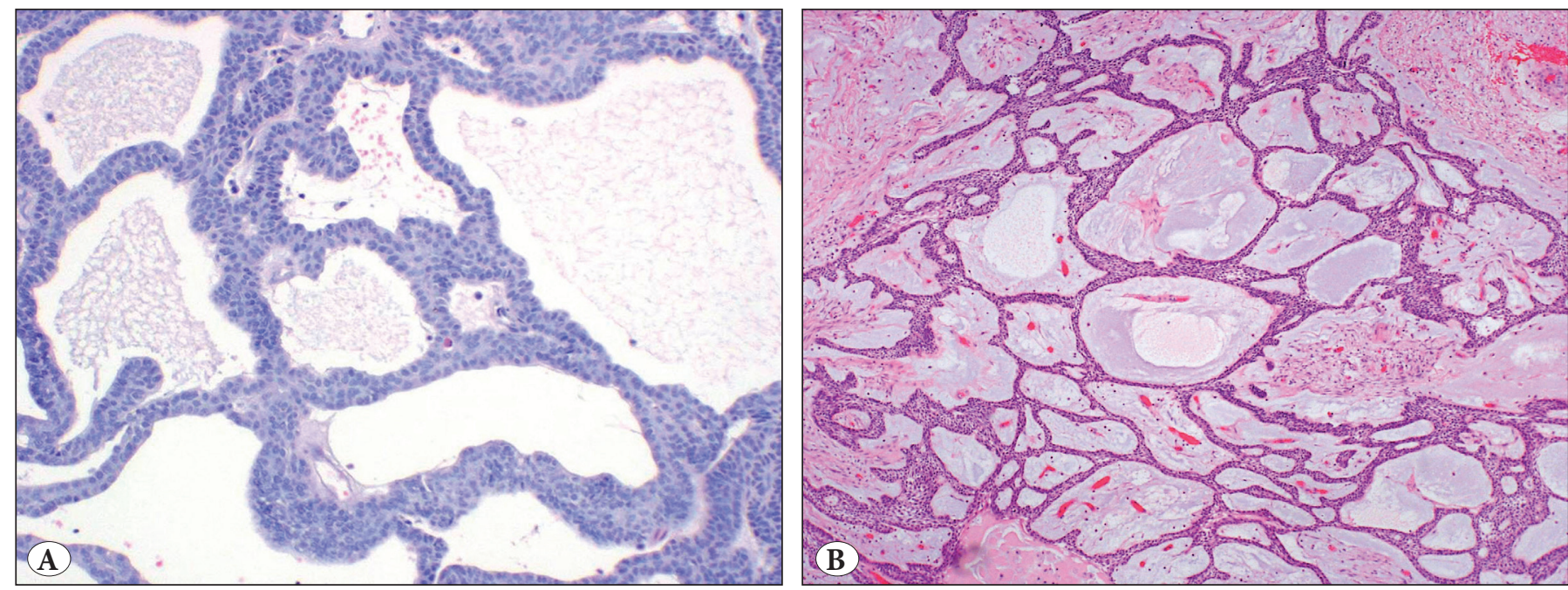

Figure 10: A) Plexiform ameloblastoma. One plexiform pattern shows thin lamina like strands of basaloid epithelial cells, often without peripheral palisading and reverse nuclear polarity (H\&E; x200). B) Plexiform ameloblastoma. Another pattern where the cords are thicker and looser and also without peripheral palisading or reverse nuclear polarity. This type often is unicystic and found in the second decade (H\&E; x100). 
pattern shows squamous differentiation centrally and the differential diagnosis always includes squamous cell carcinoma or squamous odontogenic tumor (Figure 11). The granular cell and basaloid types show either granular cell change (Figure 12) or basaloid morphology (Figure 13) respectively. With the granular cell variety, some or all of the cell can show granular cell change, often complicating diagnosis. The nuclear crowding and hypercellularity of basal cell ameloblastoma always raises a concern for malignancy but by itself is not diagnostic of malignancy. In the desmoplastic variant, the tumor cells can induce stromal desmoplasia which often compresses the neoplastic cells, resulting in loss of diagnostic peripheral palisading with reverse nuclear polarity (Figure 14). While ameloblastomas

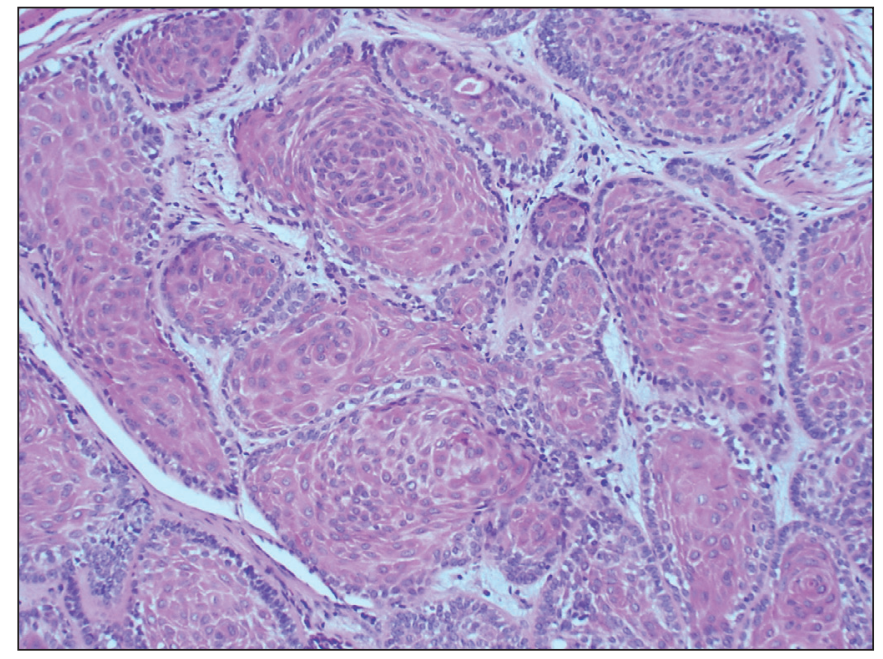

Figure 11: Acanthomatous ameloblastoma. There central cells show more mature squamous differentiation (H\&E; x200).

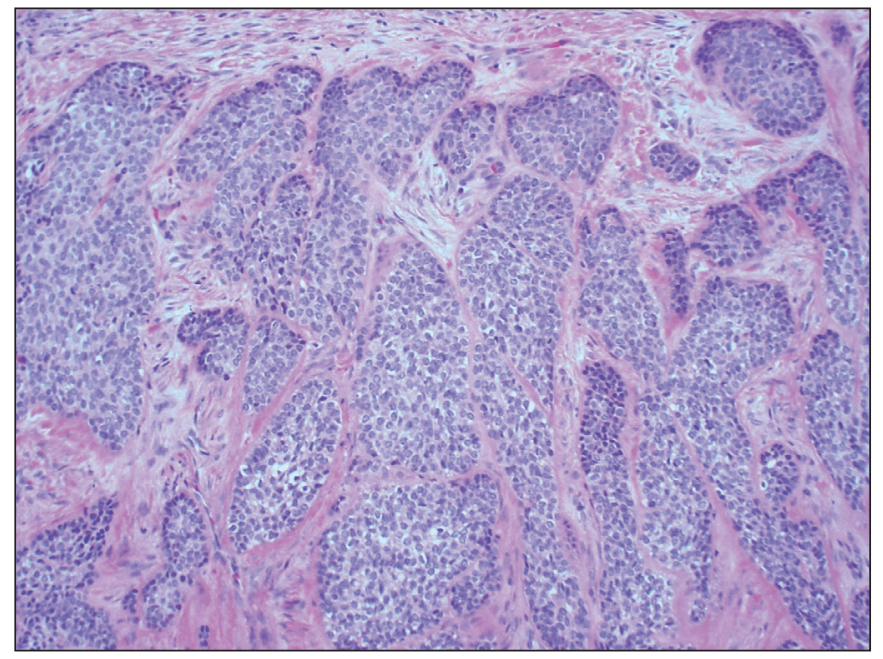

Figure 13: Basaloid ameloblastoma. The entire islands of neoplastic cells remains basaloid (H\&E; x200). can show a predominant histologic subtype, most show combinations of subtypes but all of these histopathologic types have no clinical significance (26). Their clinical behaviors are not different from conventional ameloblastomas, including desmoplastic ameloblastomas, which have distinctive clinical and radiologic features (27). One of the most genetically studied tumors with the aim of understanding their etiopathogenesis is ameloblastoma. Today, we know that mutations in genes of the MAPK pathway have been observed in almost $90 \%$ of all ameloblastomas, and BRAF V600E is the most common mutation (28-32). These genetic studies outline that a novel treatment of aggressive and/or recurrent ameloblastoma can be BRAF-targeted therapy. Another commonly

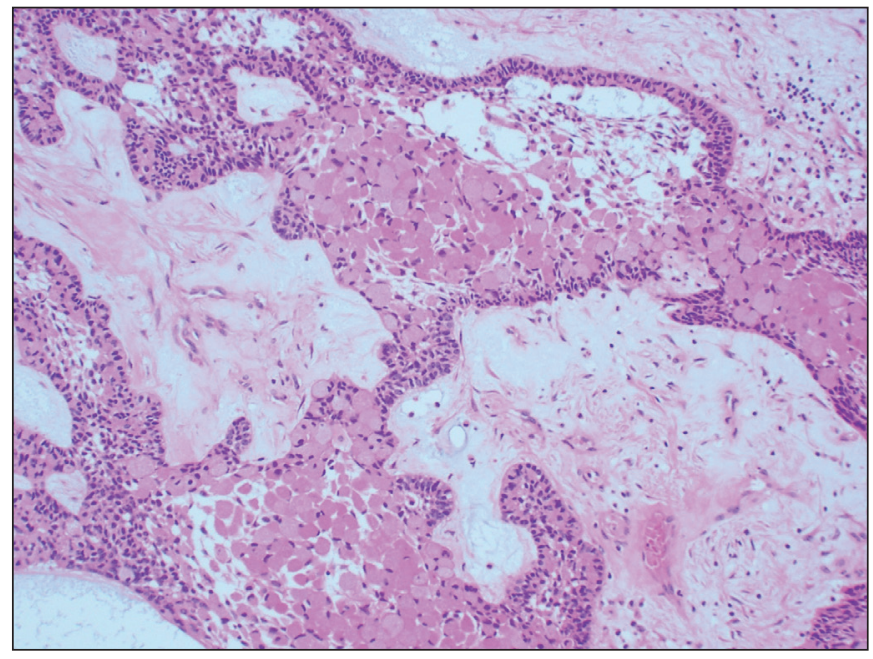

Figure 12: Granular cell ameloblastoma. Any or all of the cells of ameloblastoma can accumulate lysosomes and show granular cell change (H\&E; $\mathrm{x} 200)$.

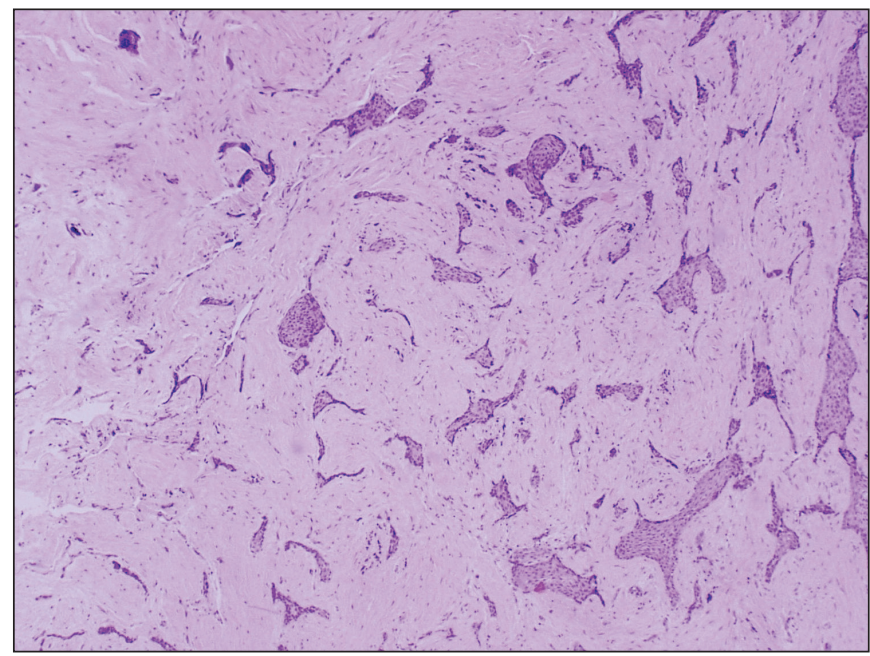

Figure 14: Desmoplastic ameloblastoma. Marked stromal desmoplasia compresses the neoplastic islands of epithelium (H\&E; x100). 
observed mutation is SMO, in the non-MAPK pathway $(31,32)$. These results might define two different genetic pathways for ameloblastomas. Table II summarizes the prevalence of mutations according to localization (1).

The unicystic ameloblastoma represents an ameloblastoma, which presents as a cyst and has a lower recurrence rate following conservative removal. Three histopathologic variants were recognized in the 2005 edition and the original publication in 1978, luminal, intraluminal, and mural depending on whether only the cyst lining is affected (Figure 15) or whether solid neoplasm could be identified that had grown intraluminally or infiltrated the wall of the cyst. The most controversial type with this lesion is mural due to the higher recurrence rate with conservative treatment than with the other two types (33) Some researchers suggest that if unicystic ameloblastoma has a mural component, it should be considered as conventional ameloblastoma with extensive cystic change rather than unicystic ameloblastoma. This debate may be clarified by the next classification. BRAF V600E mutations have also been observed in a few studies $(28,29,34)$ Clearly additional evidence is needed.

The extraosseous/peripheral type shows similar histologic patterns as seen in the conventional type (35); however, no genetic alterations have yet been demonstrated although we have a case (unpublished) of extraosseous unicystic ameloblastoma with BRAF immunoreactivity by IHC.

Metastasizing ameloblastoma is an ameloblastoma that metastasizes despite its benign histologic appearance (36) This tumor, which was in the odontogenic/ameloblastic carcinoma section in the 2005 classification, is now classified under ameloblastoma, although as pointed out earlier, this decision was not unanimous.

No major changes were made in squamous odontogenic tumor (SOT), calcifying epithelial odontogenic tumor (CEOT) or adenomatoid odontogenic tumor (AOT) in this tumor group, but some additional genetic and molecular data are now available.

It has been mentioned that the cytodifferentiation of SOT might be linked with Notch receptors and their ligands (37). Even though an isolated familial case has been reported (38), genetic susceptibility is minimal. SOT consists of irregular islands of mature squamous epithelium (Figure 16). Squamous cell carcinoma and acanthomatous ameloblastoma are the largest diagnostic pitfalls but SOT lacks cytologic atypia and there is no peripheral palisading or reverse nuclear polarity.
One of the characteristic histopathologic features of CEOT is the eosinophilic, homogeneous hyaline material that is accepted as one of the amyloid proteins. Now, both the protein structure and DNA sequence of the responsible gene have been described and the protein was named provisionally as AODAM, which is encoded by exons $5-10$

Table II: Prevalence of mutations in ameloblastomas in the 2017 edition (1)

\begin{tabular}{lcccc}
\hline Location of & \multicolumn{4}{c}{ Prevalence of mutations } \\
\cline { 2 - 5 } ameloblastoma & BRAF & RAS family & FGFR2 & SMO \\
\hline Maxilla & $20 \%$ & $40 \%$ & $15 \%$ & $55 \%$ \\
\hline Mandible & $72 \%$ & $5 \%$ & $5 \%$ & $5 \%$ \\
\hline
\end{tabular}

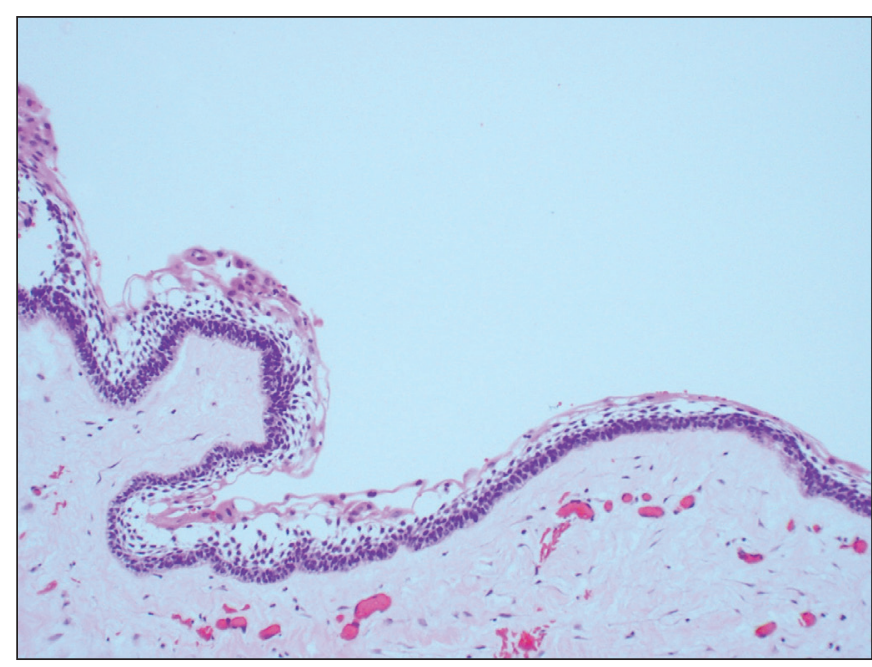

Figure 15: Unicystic ameloblastoma where only the epithelial lining of the cyst shows ameloblastic change with palisading and reverse nuclear polarity. The suprabasilar areas often loosen like stellate reticulum and compression of the surface layer often produces a "red, white and blue" effect (H\&E; x100).

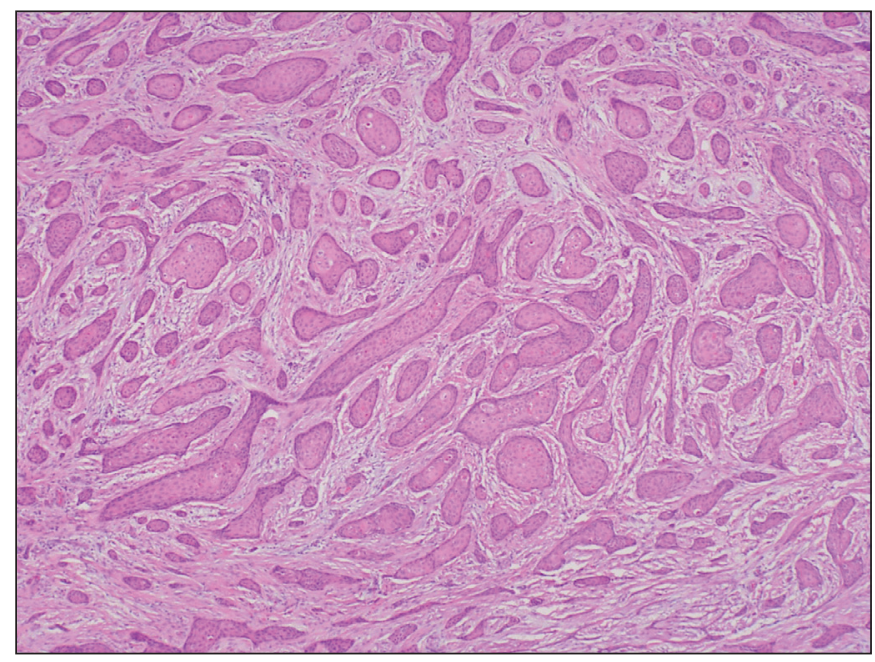

Figure 16: Squamous odontogenic tumor. Irregular islands of mature squamous epithelium (H\&E; x100). 


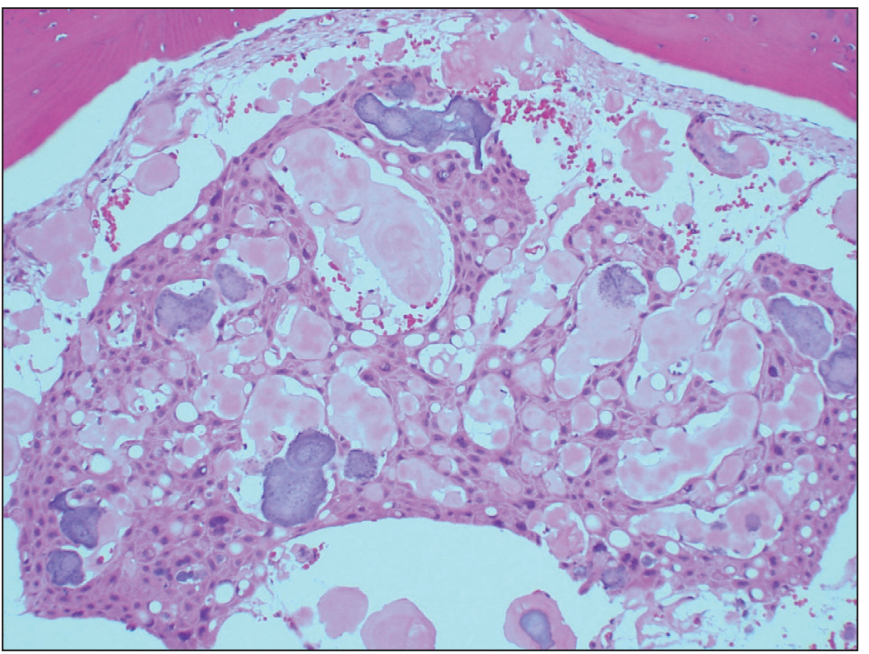

Figure 17: Calcifying epithelial odontogenic tumor. Islands of polyhedral epithelial cells without peripheral palisading or reverse nuclear polarity with amorphous masses of extracellular matrix that calcifies (H\&E; x200).

of the odontogenic ameloblast-associated protein (ODAM) locus $(39,40)$. The material shows a reaction with amyloid stains. Mutations of $\mathrm{PTCH}$, which is characteristically associated with nevoid basal cell carcinoma syndrome, have been identified in a small series of CEOT; however, CEOT is not a component of that syndrome (41). Histologically, CEOT is an epithelial tumor that lacks peripheral features of ameloblastoma. Its salient diagnostic feature is identifying the extracellular amyloid protein it excretes that has a tendency to calcify (Figure 17). The cells can be pleomorphic which raises the possibility of malignancy but the mitotic rate is low.

AOT has always been difficult to classify because of its developmental histogenetic origin because some tumors contain larger areas of calcified matrix, some of which has reported as dentinoid or cementoid. And yet it is impossible for an epithelial odontogenic tumor to produce mesenchymal dental hard tissue. It seems that this debate is going to continue for a while. Also, it is debated about whether AOT is neoplastic or hamartomatous, and immunohistochemical results might reflect the hamartomatous behavior of AOT $(42,43)$. Although no molecular anomaly was observed within exon 3 of CTNNB1 ( $\beta$-catenin gene), strong cytoplasmic expression of $\beta$-catenin has been reported (44). Further studies are needed to explain the specific regulation of $\beta$-catenin in the pathogenesis of AOT. Histologically, the most diagnostic features are the rosette or duct-like structures (Figure 18).

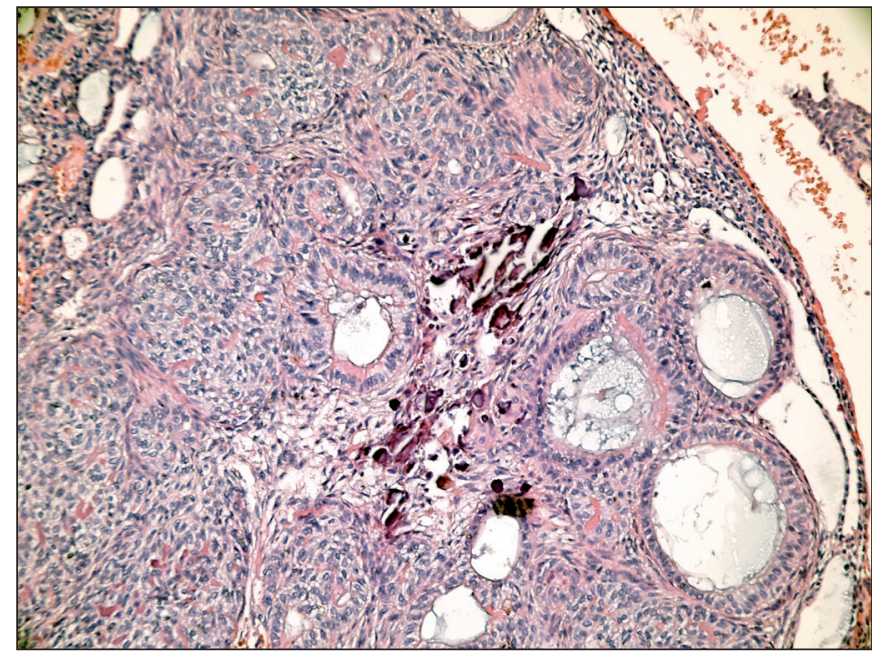

Figure 18: Adenomatoid odontogenic tumor. Characteristic rosette or duct-like spaces (H\&E; x200).

\section{BENIGN ODONTOGENIC TUMORS, MIXED}

- Ameloblastic fibroma

- Primordial odontogenic tumor

- Odontoma

- Compound type

- Complex type

- Dentinogenic ghost cell tumor

Some major changes were also made in the classification scheme for this tumor group. Although odontoameloblastomas and calcifying cystic odontogenic tumors were excluded from the mixed odontogenic classification, the new entity of primordial odontogenic tumor was included for the first time in the 2017 classification.

Odontoameloblastoma (45), which was added to the 2005 classification, is no longer used because the ameloblastic areas in odontomas do not justify a separate entity and, in fact, the combination of ameloblastoma and odontoma histologically is more likely to be an ameloblastoma arising in the odontomas from primitive ectoderm.

Calcifying cystic odontogenic tumor was excluded from this tumor scheme and moved back into the developmental cyst category as calcifying odontogenic cyst (see odontogenic cysts section) because there was no evidence presented that the cystic COCs were neoplastic. 
In 2005, the mixed odontogenic tumor, consisting of odontogenic ectomesenchyme resembling dental papilla and epithelial strands, and nests resembling dental lamina with occasional formation of enamel organs had been referred to according to the presence or absence of dental hard tissue and were termed as ameloblastic fibroma (Figure 19), ameloblastic fibrodentinoma and ameloblastic fibro-odontoma (46). The last two were excluded from the 2017 classification because there is some evidence that once dental hard tissues are formed, these lesions are programmed to develop into odontomas (47-49). The genetic profile of ameloblastic fibroma needs larger numbers of case studies; however, BRAFV600E mutation and fractional allelic loss of tumor suppressor gene with a low frequency have been reported $(50,51)$.

Primordial odontogenic tumor (POT) was included for the first time in this section in the 2017 WHO classification. POT is a mixed odontogenic tumor with fewer than one dozen reported cases; some additional cases may have been described under different names. POTs are composed of variable cellular loose fibrous tissue resembling dental papilla, entirely surrounded by cuboidal-to-columnar epithelium similar to inner enamel epithelium of the enamel organ (52,53) (Figure 20). The young age of patients, affected mandible, well-circumscribed pericoronal radiolucencies, and histopathologic uniformity are clues to the diagnosis. Regarding immunohistochemical staining, the mesenchymal tissue shows positivity with vimentin, and the epithelial lining is positive for CK AE1/AE3, CK5, CK14, and CK19, but negative for CK18 and CK20. The

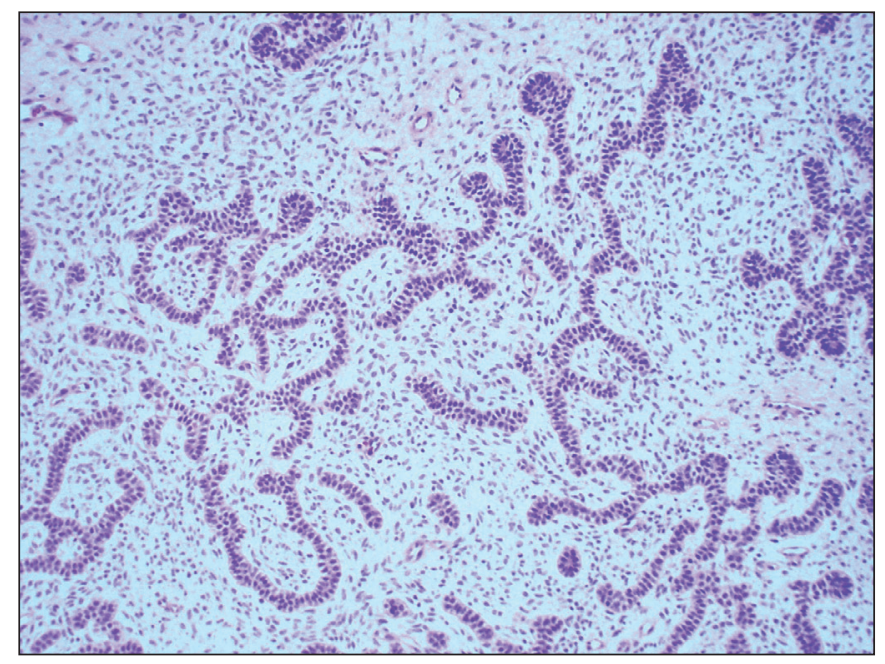

Figure 19: Ameloblastic fibroma. Lamina-like strands of epithelium in an evenly distributed cellular embryonic ectomesenchymal stoma without cytologic atypia (H\&E; x100). proliferation index is very low at $<2 \%$. All cases were treated with conservative surgery and no recurrence has been reported (1).

Odontomas have been updated without remarkable changes. Complex and compound types are explained under the odontoma heading, which were separate sections in 2005. The speculative relationship between developing odontomas and ameloblastic fibromas/ameloblastic fibrodentinoma and ameloblastic fibro-odontoma has been added. Odontomas are comprised of both odontogenic hard and soft tissues. The primary diagnostic features are demonstrating dentin which is a matrix similar to bone but without cellular inclusions and containing tubules. Enamel matrix should also be seen; it has a prismatic structure that morphologically looks like fish scales (Figures 21A,B).

Dentinogenic ghost cell tumors have been updated and a profile of immunohistochemical features has been added. The tumor is a relatively rare type of ghost cell lesion characterized by ameloblastoma-like islands of epithelial cells in a mature connective tissue stroma with accumulation of ghost cells. Histopathologically, the most challenging differential diagnosis is ameloblastoma with ghost cells. The new edition outlined that the proportion of ghost cells $(>1-2 \%)$ and the presence of dentinoid are important features in establishing this difference $(1,54)$ (Figure 22). The epithelial cells might react with CK5, CK7, CK14, and CK19. The Ki-67 proliferation index is $<5 \%$ (55). The recommended surgical treatment is segmental resection because of the high recurrence rate and local invasive nature of the tumor (56).

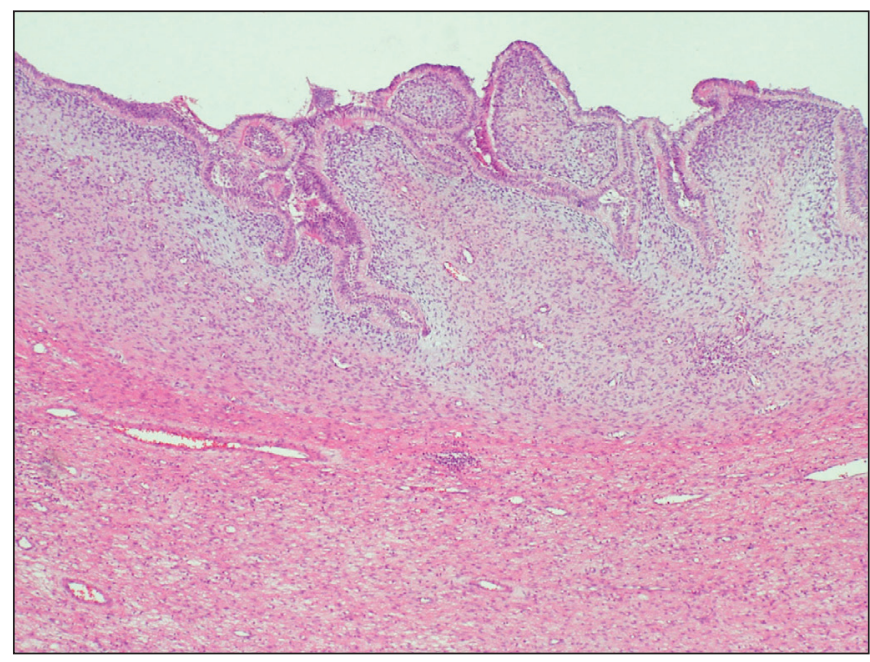

Figure 20: Primordial odontogenic tumor. Primitive ectomesenchyme lined by columnar epithelial cells (H\&E; x100). 

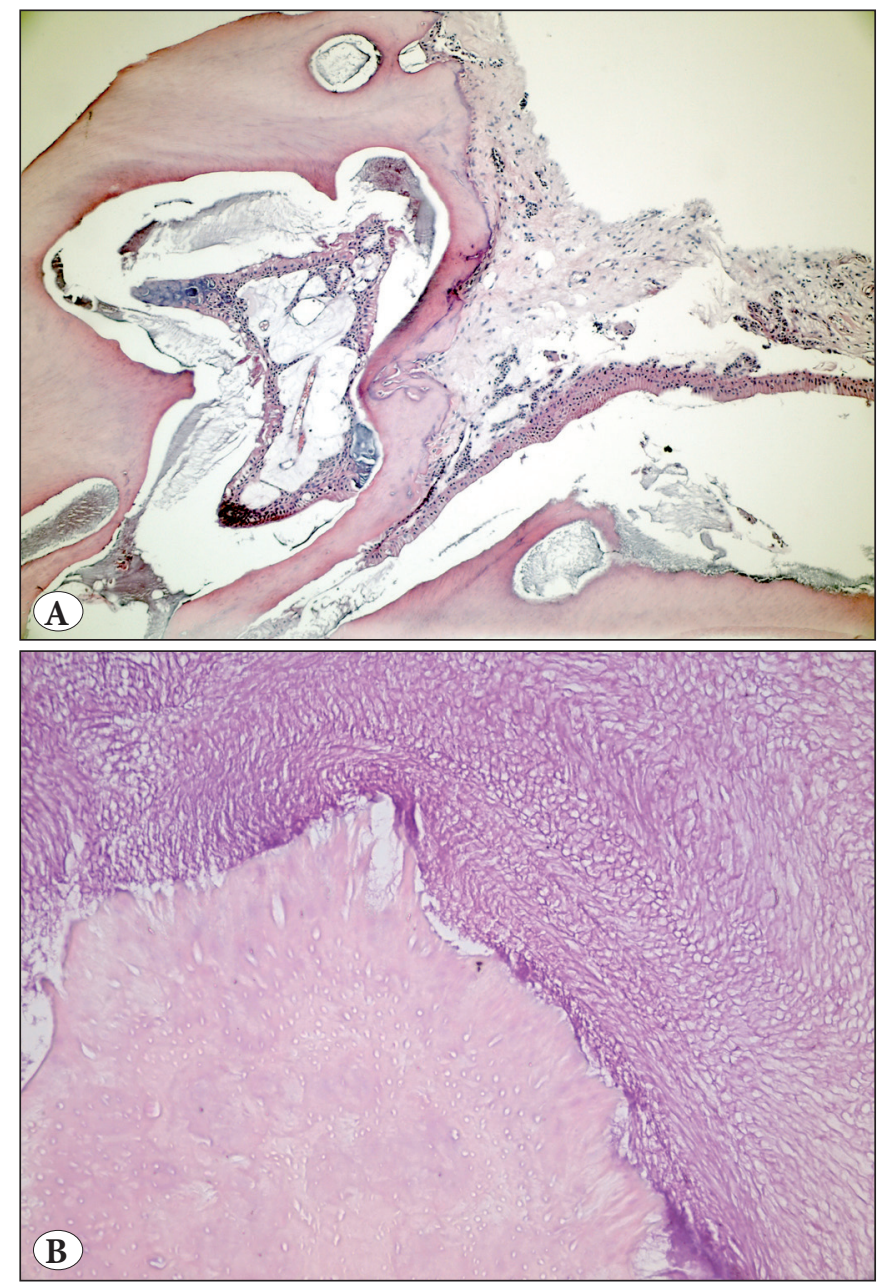

Figure 21: A) Odontoma. Mixture of odontogenic hard and soft tissues (H\&E x200). B) Odontoma. Lower portions is acellular dentin containing tubules. Superior portion is enamel matrix (H\&E; 400$)$.

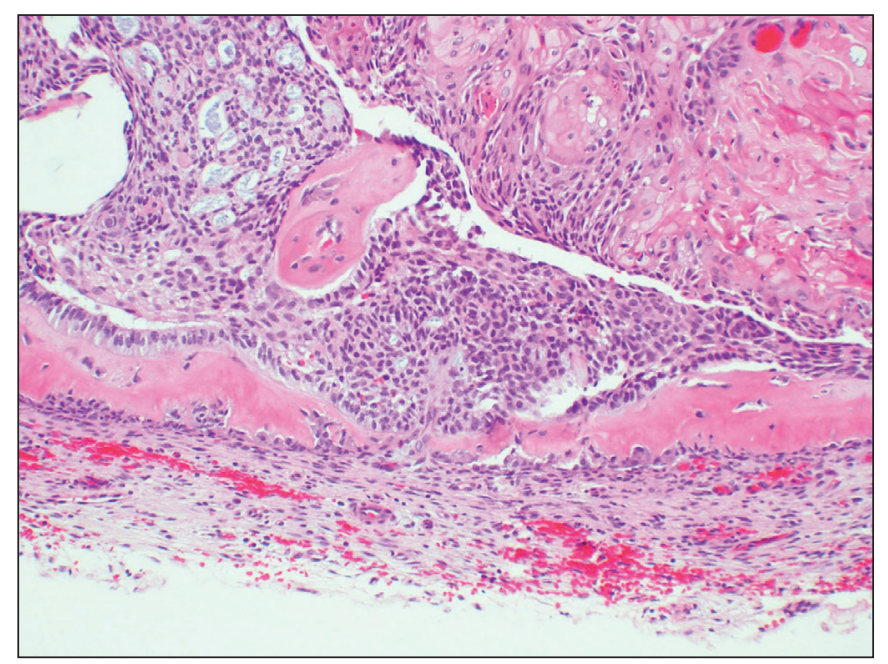

Figure 22: Dentinogenic ghost cell tumor. Band of atubular dentin inferiorly and ghost cells superiorly (H\&E; x200).

\section{BENIGN ODONTOGENIC TUMORS, MESENCHYMAL}

- Odontogenic fibroma

- Odontogenic myxoma/myxofibroma

- Cementoblastoma

- Cemento-ossifying fibroma

There were no major changes for mesenchymal odontogenic tumors in the fourth edition, with the exception of the addition of the term 'cemento-ossifying fibroma (COF)'. In fact, ossifying fibroma is used to describe a benign bone-producing fibrous neoplasms of the skeleton which is separated into two main clinicopathologic entities: cemento-ossifying fibroma and juvenile ossifying fibroma, the later which is further divided into two distinct types (57). Cemento-ossifying fibroma has been variously called ossifying fibroma, cementifying fibroma, and cementoossifying fibroma. In the 2017 classification, the latter is preferred because of its descriptive value, and more importantly, it was classified under odontogenic tumors to distinguish it from the juvenile types. However, it is still a fibro-osseous lesion and discussed in detail with the other ossifying fibromas in the fibro-osseous lesions section of the last WHO edition. Histologically it is characterized by a variably cellular fibroblastic stroma with varying amounts of matrix; some resembling bone as trabeculae with cellular inclusions and some resembling "cementum", often more rounded or globular and acellular (Figure 23). COF is a characteristic benign fibro-osseous lesion whose definitive classification is best achieved with clinical and radiographic correlation.

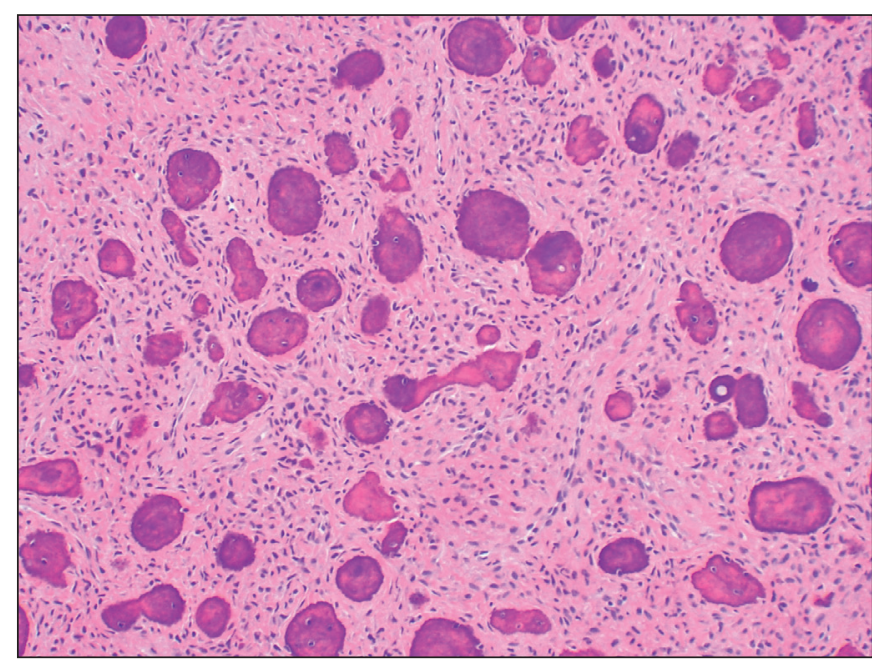

Figure 23: Cemento-ossifying fibroma. Spindled fibroblastic stroma with trabecular and globular matrix (H\&E; x200). 


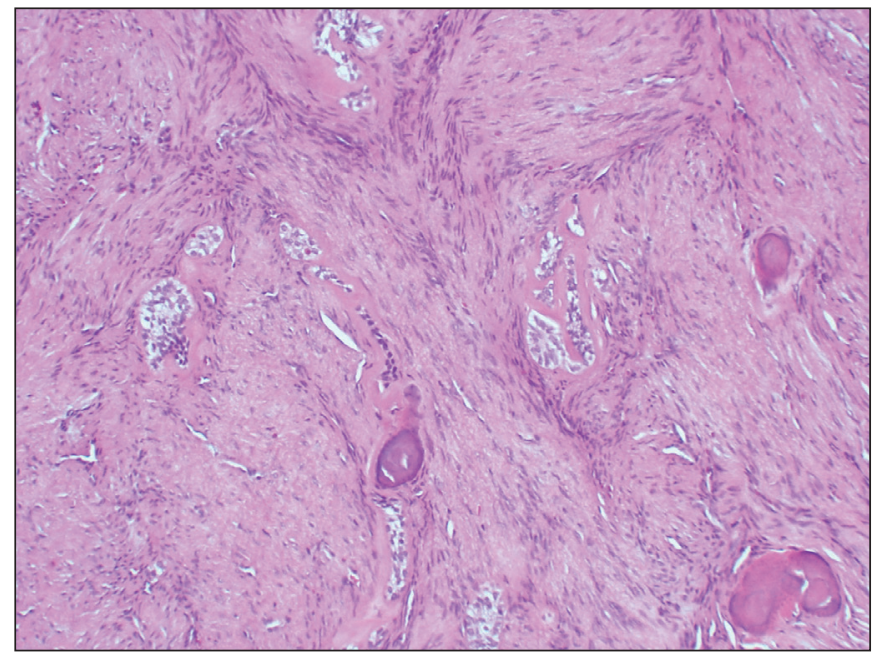

Figure 24: Odontogenic fibroma. Mature fasciculating spindled stroma with small islands of odontogenic epithelium, often with clear cell change and calcifications (H\&E; x200).

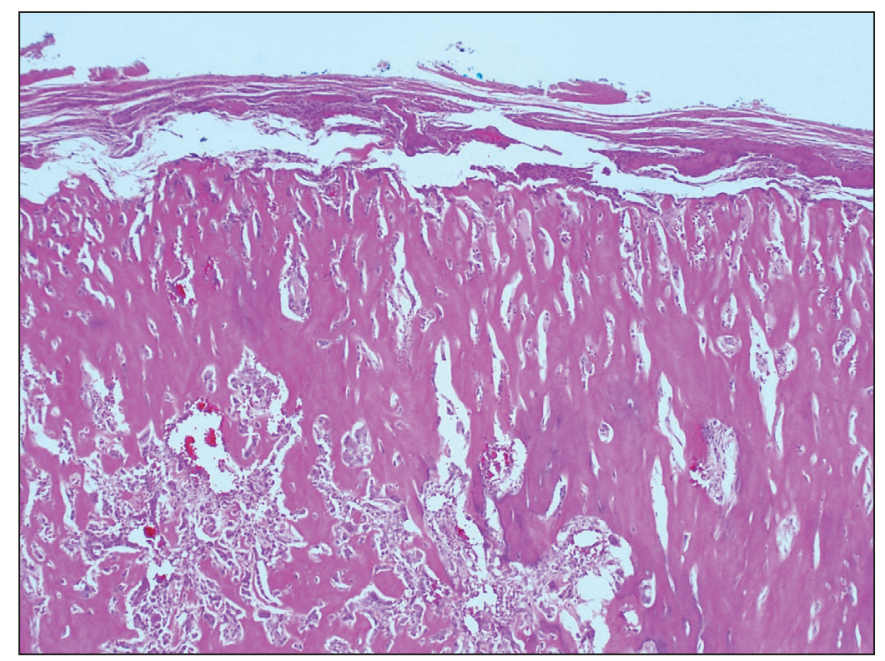

Figure 26: Cementoblastoma. Characteristic perpendicular arrangement of the peripheral trabeculae to the external capsule (H\&E; x100).

A small change has also been made for the odontogenic fibroma (OF) subclassification. In 2005, OF was applied to two histopathologic types of lesions, the epithelium rich (WHO-type or complex) and epithelium poor types (simple type) $(58,59)$. In the present classification, the subtypes were excluded due to poorly defined and documented epithelialpoor types (2). The WHO currently defines OF as a rare neoplasm of mature fibrous connective tissue, with variable amounts of inactive-looking odontogenic epithelium, with or without evidence of calcification (Figure 24).

The new entity, sclerosing odontogenic carcinoma, might have some similar histologic features to central odontogenic fibroma and should be considered in the differential diagnosis.

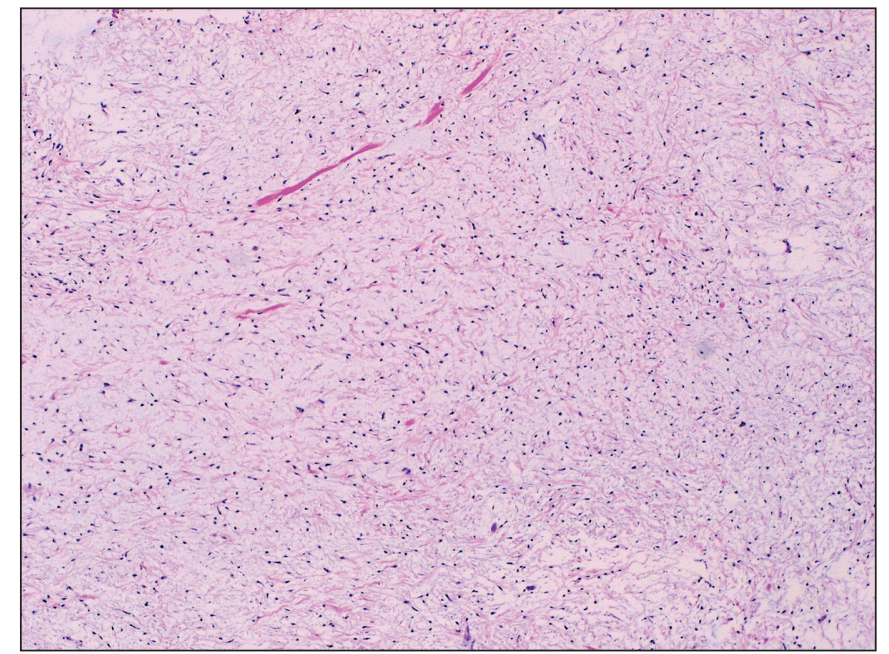

Figure 25: Odontogenic myxoma. Highly myxomatous tumor of stellate to spindled mesenchymal cells without cytologic atypia (H\&E; x100).

Odontogenic myxoma/fibromyxoma and cementoblastoma have been updated and continue in the 2017 classification. The information of isolated odontogenic myxoma cases that appeared associated with nevoid basal cell carcinoma syndrome was added to the genetic profiles of the tumor (60). Odontogenic myxomas histologically are myxoid and hypocellular due to overproduction of glycosaminoglycans (Figure 25). Diagnostic pitfalls might include normal anatomic structures that look similar histologically; namely dental papillae of developing teeth and hyperplastic dental follicles around unerupted teeth. Cementoblastomas have characteristic radiographic features of a sclerotic tumor fused with tooth root(s) and surrounded by a radiolucent zone. Histologically areas are identical to osteoblastoma but the tumor is fused to a tooth root and peripherally the trabeculae of "cementum" are perpendicular to the capsule (Figure 26).

Peripheral/extraosseous types of odontogenic tumors have been updated but remain relatively unchanged.

\section{ODONTOGENIC CYSTS}

- Developmental origin

- Dentigerous cyst

- Odontogenic keratocyst

- Lateral periodontal and botryoid odontogenic cyst

- Gingival cyst

- Glandular odontogenic cyst

- Calcifying odontogenic cyst

- Orthokeratinized odontogenic cyst

- Inflammatory origin

- Radicular cyst

- Collateral inflammatory cyst 
There has been no definitive revision of the classification of odontogenic cysts since 1992. Because the 2005 WHO classification of head and neck tumors did not include odontogenic cysts, a few changes in terminology of 'cystic' lesions have occurred $(3,61)$. Two of the most significant changes in 2017 were that 'calcified cystic odontogenic tumor' and 'keratocystic odontogenic tumor' were moved from the neoplastic category (2005) back into the cyst category (2017). Calcified cystic odontogenic tumor is now classified as a 'calcifying odontogenic cyst;' and keratocystic odontogenic tumor is now listed as 'odontogenic keratocyst (OKC)' in the 2017 classification of developmental odontogenic cysts. In fact, the neoplastic designations of the 2005 classification were never been fully accepted, especially by many oral pathologists. The working group did acknowledge that there was at least some justification, namely mutations of the PTCH gene, to justify reclassifying OKC as neoplastic in 2005, but they agreed that the overall evidence was not sufficiently compelling at this time to continue $\mathrm{OKC}$ as a neoplasm. The working group felt there was never sufficient evidence to classify cystic ghost cells lesions as neoplasms.

The term of odontogenic keratocyst was first used to describe all odontogenic cysts that contain keratin formations in the 1950s (62). When keratin formation started to determine a range of other cysts, the distinct distinction was made for a specific cyst type named keratocyst. The odontogenic keratocyst term, synonymous with primordial cyst, was used in the 1992 classification (63). The 2005 classification reclassified this unique lesion as a neoplasm and renamed it as 'keratocystic odontogenic tumor' because of the high recurrence rate, aggressive clinical behavior, association with nevoid basal cell carcinoma syndrome, and mutations in the PTCH tumor suppressor gene (3). The 2017 classification reverted back to the original and well accepted terminology of OKC because many papers showed that the PTCH gene mutation could be found in non-neoplastic lesions, including dentigerous cysts (64), and furthermore, many researchers suggested that resolution of the cyst after marsupialization was not compatible with a neoplastic process (65-67). In 2017, the term primordial cyst was not used in the classification, but keratocystic odontogenic tumor was carried forward as a synonym of OKC. It is important and clinically relevant to separate OKCs from the other odontogenic cysts. They have diagnostic histologic features and are characterized by a uniform stratified squamous epithelial lining without rete ridges. They have palisaded and hyperchromatic basal cells and often a corrugated surface layer of parakeratin (Figure 27).

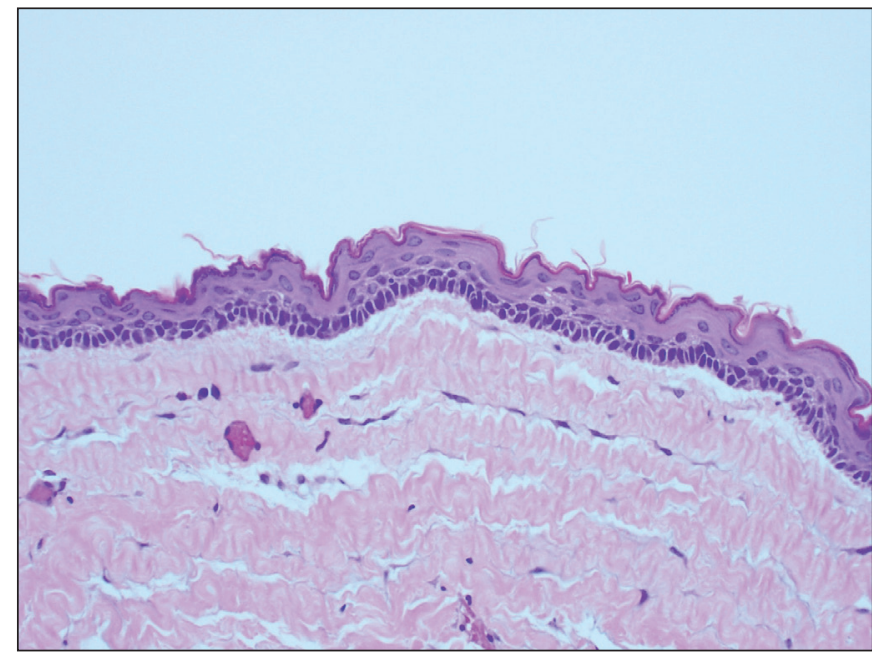

Figure 27: Odontogenic keratocyst. Uniform stratified squamous epithelium with basilar palisading, hyperchromasia and overlying corrugated parakeratin (H\&E; x400).

Ghost cell lesions were classified as odontogenic tumors and cysts in the 1992 classification, with COC representing the non-neoplastic cystic ones and dentinogenic ghost cell tumor as the solid neoplastic variant which might have an infiltrative pattern of growth $(63,68)$. The 2005 classification addressed this dilemma and determined that both were neoplastic, naming them as calcifying cystic odontogenic tumors for cystic forms and dentinogenic ghost cell tumors for solid forms (3). In the 2017 classification, the cystic form of tumor was returned to the developmental cyst scheme and the solid form was retained as a mixed odontogenic neoplasm. COCs are simple cysts lined by epithelium with focal accumulations of ghost cells (Figures 28A,B). Their relationship with other odontogenic tumors has been well established in the 2017 classification, unlike in 2005, and odontomas are associated in about $20 \%$ of cases and occasionally ameloblastic fibroma, ameloblastic fibro-odontoma or adenomatoid odontogenic tumor-like areas can be detected (19).

Orthokeratinized odontogenic cyst (OOC) is a developmental odontogenic cyst that is entirely or predominantly lined by orthokeratinized stratified squamous epithelium. It was originally referred to as a type of $\mathrm{OKC}$ and described in 1981 (69). In 2017, the classification of this cyst was accepted as a separate entity for the first time. It differs both clinically and histopathologically from OKC. OOCs are not associated with any syndromes, do not have high recurrence rates, and do not show aggressive clinical behavior. Histopathologically, a prominent palisaded basal layer of epithelial lining, characteristic of the $\mathrm{OKC}$, is not present $(2,70)$ (Figure 29). 

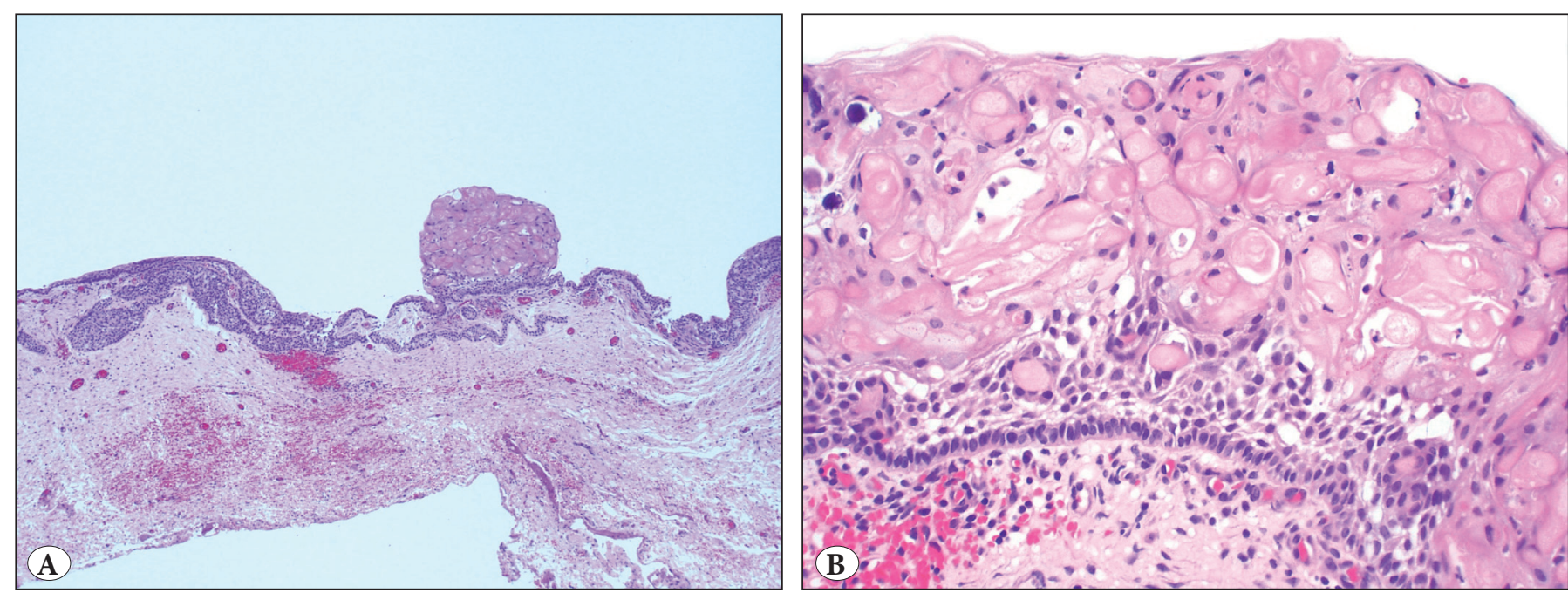

Figure 28: A) Calcifying odontogenic cyst with focus of ghost cells (H\&E x100). B) Calcifying odontogenic cyst. Characteristic ghost cells identical to those seen in pilomatrixoma and craniopharyngioma (H\&E; $\mathrm{x} 400)$.

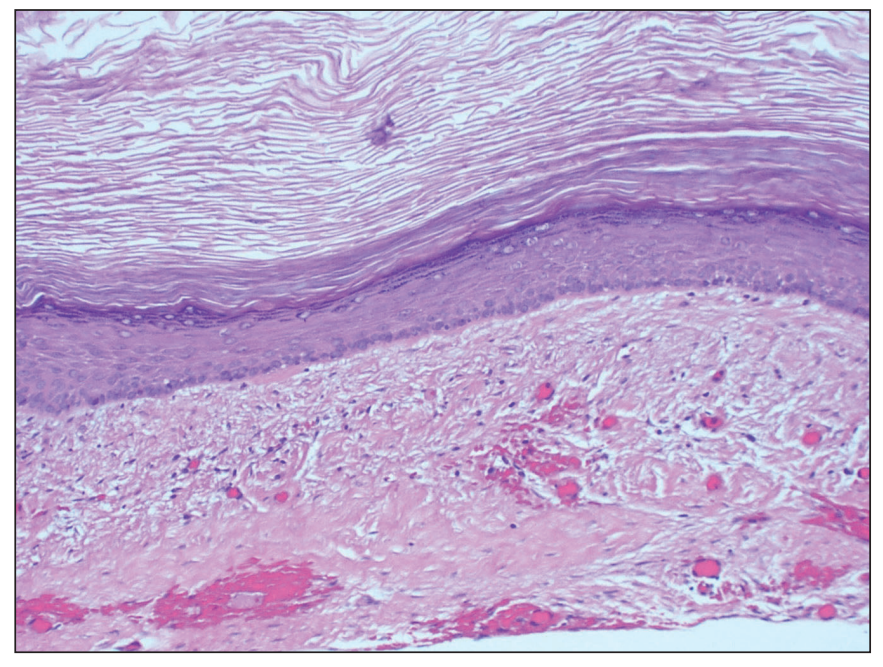

Figure 29: Orthokeratinized odontogenic cyst. Luminal side is orthokeratinized. Note lack of basilar palisading and nuclear hyperchromatism (H\&E; x200).

Glandular odontogenic cyst (GOC) was updated with new diagnostic criteria and continues in the 2017 classification. There are ten different histopathologic features and observation of at least seven criteria is suggested to make a definitive GOC diagnosis (71) (Figure 30). The new edition especially outlined that GOCs might have similar morphologic features with central mucoepidermoid carcinoma. To distinguish these two lesions from each other is very important; however, it can be impossible in a small incisional biopsy. However, GOCs do not show MAML2 gene rearrangements, which are often found in central mucoepidermoid carcinomas (72).

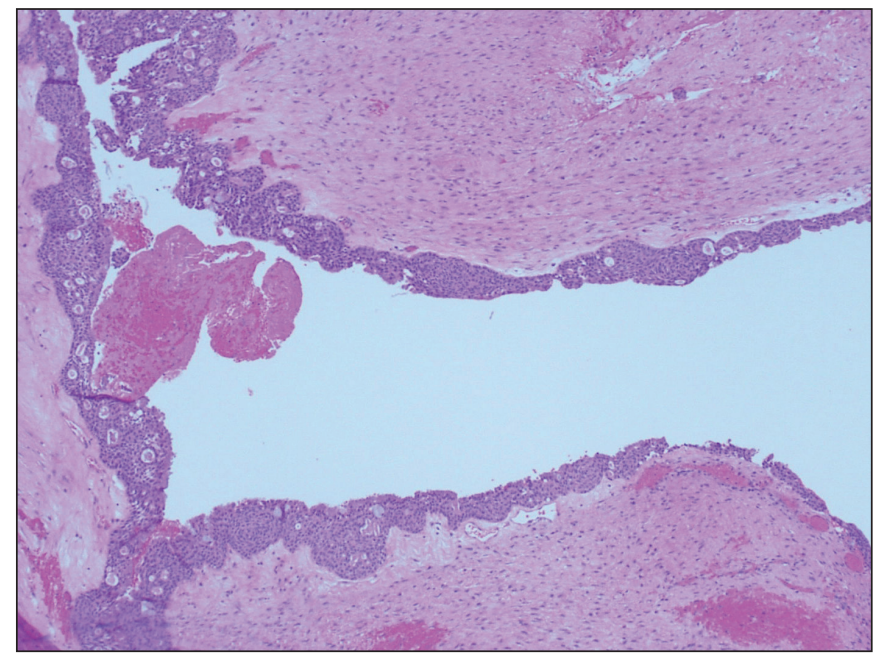

Figure 30: Glandular odontogenic cyst. Lining thickness is variable and may contain mucous cells, clear cells, intraepithelial lumina, cilia and hobnailing of the luminal surface (H\&E; x100).

No other major changes were made in the odontogenic cysts group. Other developmental odontogenic cysts such as gingival cysts, dentigerous cysts, and lateral periodontal cysts have minor changes and continue in the 2017 classification. Lateral periodontal cysts were added to the classification in 1992 and reference was made to its multilocular variant of botryoid cyst (63). Botryoid odontogenic cyst terminology has now been added under developmental cysts, as a polycystic variant of lateral periodontal cysts. 'Gingival cyst of infants' and 'gingival cyst in adults' of the 1992 classification have been collected under the heading of gingival cysts. Also 'eruption cyst' 


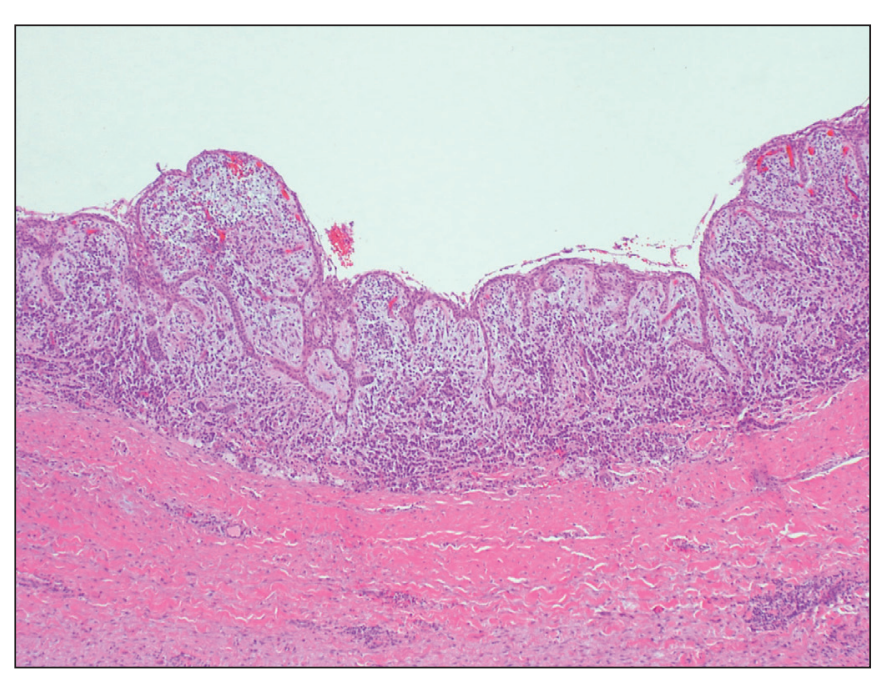

Figure 31: Radicular cyst. Inflammatory odontogenic cyst secondary to a devitalized tooth. Stratified squamous epithelium with rete ridges and inflamed connective tissue wall (H\&E x100).

had a separate header in the 1992 classification, and now it is included in the dentigerous cyst section and described as a variant of dentigerous cysts found in the soft tissues overlying an erupting tooth.

Inflammatory cysts have a few changes. In the 1992 classification, this group was divided into radicular cysts with subclassification and paradental cysts. In the 2017 classification, there are two main types: radicular cysts and inflammatory collateral cysts. Radicular cysts (apical periodontal cysts) are the most common cyst of the jaw with inflammatory origin associated with non-vital teeth (73) (Figure 31), and under the radicular cyst header, the residual cyst and lateral radicular cyst have been mentioned with residual cyst remaining in the jaw after extraction of the affected tooth and a lateral radicular cyst associated with a lateral root canal, respectively. Other inflammatory cysts are collected under the name of inflammatory collateral cysts, which has been used for the first time. These cysts are 'paradental cysts' arising on the lower third molars and 'mandibular buccal bifurcation cysts' arising on the buccal surface of erupting lower first and second molars (74). The etiopathogenesis of these lesions is uncertain. They might arise either from reduced enamel epithelium or from sulcular/junctional epithelium (75).

In conclusion, this review briefly highlights updates in the 2017 WHO classification of odontogenic tumors and cysts and illustrates the most important histologic features. This classification is based on a large number of studies that have helped to better define the tumor and cyst classification. The knowledge of all these changes, especially regarding immunohistochemical markers and genetic/molecular data, provide a more uniform approach to the diagnosis of lesions for pathologists to reference.

\section{CONFLICT of INTEREST}

The authors have declared no conflict of interest.

\section{REFERENCES}

1. Odontogenic and maxilofacial bone tumours. In: El-Naggar AK, Chan JKC, Grandis JR, Takata T, Slootweg P, editors. WHO classification of Head and Neck Tumours. 4th ed. Lyon: IARC; 2017.205-60.

2. Wright JM, Vered M. Update from the 4th Edition of the World Health Organization Classification of Head and Neck Tumours: Odontogenic and maxillofacial bone tumors. Head Neck Pathol. 2017;11:68-77.

3. Odontogenic tumors. In: Barnes L, Eveson J, Reichart P, Sidransky D, editors. World Health Organization classification. Pathology and Genetics of Head and Neck Tumors. $3^{\text {rd }}$ ed. Lyon: IARC Press; 2005.283-327.

4. Brunner P, Bihl M, Jundt G, Baumhoer D, Hoeller S. BRAF p.V600E mutations are not unique to ameloblastoma and are shared by other odontogenic tumors with ameloblastic morphology. Oral Oncol. 2015;51:e77-8.

5. Bologna-Molina R, Mosqueda-Taylor A, Molina-Frechero N, Mori-Estevez AD, Sán- chez-Acuña G. Comparison of the value of PCNA and Ki-67 as markers of cell proliferation in ameloblastic tumors. Med Oral Patol Oral Cir Bucal. 2013;18:e174-9.

6. Lei Y, Jaradat JM, Owosho A, Adebiyi KE, Lybrand KS, Neville BW, Müller S, Bilodeau EA. Evaluation of SOX2 as a potential marker for ameloblastic carcinoma. Oral Surg Oral Med Oral Pathol Oral Radiol. 2014;117:608-16.e1.

7. Moro A, Foresta E, Gasparini G, Pelo S, Forcione M, Cristallini EG, Toraldo M, Lorenzo C, Falchi M, Saponaro G. Ameloblastic carcinoma of the maxilla: A case report and an updated review of the literature. Oncol Lett. 2016;12:4339-50.

8. Bodner L, Manor E, Shear M, van der Waal I. Primary intraosseous squamous cell carcinoma arising in an odontogenic cyst: A clinicopathologic analysis of 116 reported cases. J Oral Pathol Med. 2011;40:733-8.

9. Wenguang X, Hao S, Xiaofeng Q, Zhiyong W, Yufeng W, Qingang H, Wei H. Prognostic Factors of Primary Intraosseous Squamous Cell Carcinoma (PIOSCC): A retrospective review. PLoS One. 2016;11:e0153646.

10. Shinoda T, Iwata H, Nakamura A, Ohkubo T, Yoshimi N, Sugie S, Tanaka T, Kato K. Cytologic appearance of carcinosarcoma (malignant ameloblastoma and fibrosarcoma) of the maxilla. A case report. Acta Cytol. 1992;36:132-6.

11. Chikosi R, Segall N, Augusto P, Freedman P. Odontogenic carcinosarcoma: Case report and literature review. J Oral Maxillofac Surg. 2011;69:1501-7.

12. Koutlas IG, Allen CM, Warnock GR, Manivel JC. Sclerosing odontogenic carcinoma: A previously unreported variant of a locally aggressive odontogenic neoplasm without apparent metastatic potential. Am J Surg Pathol. 2008;39:1613-19. 
13. Irié T, Ogawa I, Takata T, Toyosawa S, Saito N, Akiba M, Isobe T, Hokazono C, Tachikawa T, Suzuki Y. Sclerosing odontogenic carcinoma with benign fibro-oseous lesion of the mandible: An extremely rare case report. Pathol Int. 2010;60:694-700.

14. Tan SH, Yeo JF, Kheem Pang BN, Petersson F. An intraosseous sclerosing odontogenic tumor predominantly composed of epithelial cells: Relation to (so-called) sclero- sing odontogenic carcinoma and epithelial-rich central odontogenic fibroma. Oral Surg Oral Med Oral Pathol Oral Radiol. 2014;118:e119-25.

15. Bilodeau EA, Weinreb I, Antonescu CR, Zhang L, Dacic S, Muller S, Barker B, Seethala RR. Clear cell odontogenic carcinomas show EWSR1 rearrangaments: A noval finding and a biological link to salivary clear cell carcinomas. Am J Surg Pathol. 2013;37:1001-5.

16. Yancoskie AE, Sreekantaiah C, Jacob J, Rosenberg A, Edelman M, Antonescu CR, Fantasia JE. EWSR1 and ATF1 rearrangements in clear cell odontogenic carcinoma: Presentation of a case. Oral Surg Oral Med Oral Pathol Oral Radiol. 2014;118:e115-8.

17. Antonescu CR, Katabi N, Zhang L, Sung YS, Seethala RR, Jordan RC, Perez-Ordoñez B, Have C, Asa SL, Leong IT, Bradley G, Klieb H, Weinreb I. EWSR1-ATF1 fusion is a novel and consistent finding in hyalinizing clear cell-carcinoma of salivary gland. Genes Chromosomes Cancer. 2011;50:559-70.

18. Bilodeau ES, Hoschar AP, Barnes EL, Hunt JL, Seethala RR. Clear cell carcinoma and clear cell odontogenic carcinoma: A comparative clinicopathological and immunohistochemical study. Head Neck Pathol. 2011;5:101-7.

19. Ledesma-Montes C, Gorlin RJ, Shear M, Prae Torius F, Mosqueda-Taylor A, Altini M, Unni K, Paes de Almeida O, Carlos-Bregni R, Romero de León E, Phillips V, Delgado-Azañero W, Meneses-García A. International collaborative study on ghost cell odontogenic tumours: Calcifying cystic odontogenic tumour, dentinogenic ghost cell tumour and ghost cell odontogenic carcinoma. J Oral Pathol Med. 2008;37:302-8.

20. Del Corso G, Tardio ML, Gissi DB, Marchetti C, Montebugnoli L, Tarsitano A. Ki- 67 and p53 expression in ghost cell odontogenic carcinoma: A case report and literature review. Oral Maxillofac Surg. 2015;19:85-9.

21. Bose P, Pleasance ED, Jones M, Shen Y, Ch'ng C, Reisle C, Schein JE, Mungall AJ, Moore R, Ma Y, Sheffield BS, Thomson T, Rasmussen S, Ng T, Yip S, Lee CW, Ho C, Laskin J, Marra MA, Jones SJ. Integrative genomic analysis of ghost cell odontogenic carcinoma. Oral Oncol. 2015;51:e71-5.

22. Chikosi R, Segall N, Augusto P, Freedman P. Odontogenic carcinosarcoma: Case, report and literature review. J Oral Maxillofac Surg. 2011;69:1501-7.

23. DeLair D, Bejarano PA, Peleg M, El-Mofty SK. Ameloblastic carcinosarcoma arising in ameloblastic fibroma of the mandible: A case report and review of literature. Oral Surg Oral Med Oral Radiol Endod. 2007;103:516-20.

24. Lai J, Blanas N, Higgins K, Klieb H. Ameloblastic fibrosarcoma: Report of a case, study of immunophenotype, and comprehensive review of the literature. J Oral Maxillofac Surg. 2012;70:2007-12.

25. Williams MD, Hanna EY, El-Naggar AK. Anaplastic ameloblastic fibrosarcoma arising from recurrent ameloblastic fibroma: Restricted molecular abnormalities of certain genes to the malignant transformation. Oral Surg Oral Med Oral Pathol Oral Radiol Endod. 2007;104:72-5.
26. Hertog D, Bloemena E, Aartman IH, van-der-Waal I. Histopathology of ameloblastoma of the jaws; some critical observations based on a 40 years single institution experience. Med Oral Patol Oral Cir Bucal. 2012;17:e76-82.

27. Sun ZJ, Wu YR, Cheng N, Zwahlen RA, Zhao YF. Desmoplastic ameloblastoma - A review. Oral Oncol. 2009;45:752-9.

28. Brown NA, Rolland D, McHugh JB, Weigelin HC, Zhao L, Lim MS, Elenitoba-Johnson KS, Betz BL. Activating FGFR2RAS-BRAF mutations in ameloblastoma. Clin Cancer Res. 2014;20:5517-26.

29. Diniz MG, Gomes CC, Guimarães BV, Castro WH, Lacerda JC, Cardoso SV, de Faria PR, Dias FL, Eisenberg AL, Loyola AM, Gomez RS. Assessment of BRAFV600E and SMOF412E mutations in epithelial odonto- genic tumours. Tumour Biol. 2015;36:5649-53.

30. Kurppa KJ, Catón J, Morgan PR, Ristimäki A, Ruhin B, Kellokoski J, Elenius K, Heikinheimo K. High frequency of BRAF V600E mutations in ameloblastoma. J Pathol. 2014;232:492-8.

31. Sweeney RT, McClary AC, Myers BR, Biscocho J, Neahring L, Kwei KA, Qu K, Gong X, Ng T, Jones CD, Varma S, Odegaard JI, Sugiyama T, Koyota S, Rubin BP, Troxell ML, Pelham RJ, Zehnder JL, Beachy PA, Pollack JR, West RB. Identification of recurrent SMO and BRAF mutations in ameloblastomas. Nat Genet. 2014;46:722-5.

32. Brown NA, Betz BL. Ameloblastoma: A review of recent molecular pathogenetic discoveries. Biomark Cancer. 2015;7:1924.

33. Li TJ, Kitano M, Arimura K, Sugihara K. Recurrence of unicystic ameloblastoma: A case report and review of the literature. Arch Pathol Lab Med. 1998;122:371-4.

34. Pereira NB, Pereira KM, Coura BP, Diniz MG, de Castro WH, Gomes CC, Gomez RS. BRAFV600E mutation in the diagnosis of unicystic ameloblastoma. J Oral Pathol Med. 2016;45:780-5.

35. Smullin SE, Faquin W, Susarla SM, Kaban LB. Peripheral desmoplastic ameloblastoma: Report of a case and literature review. Oral Surg Oral Med Oral Pathol Oral Radiol Endod. 2008;105:37-40.

36. Rizzitelli A, Smoll NR, Chae MP, Rozen WM, Hunter-Smith DJ. Incidence and overall survival of malignant ameloblastoma. PLoS One. 2015;10:e0117789.

37. Siar CH, Nakano K, Ng KH, Tomida M, Nagatsuka H, Kawakami T. Squamous odontogenic tumor of the mandible: A case report demonstrating immunoexpression of Notch1, 3, 4, Jagged1 and Delta1. Eur J Med Res. 2010;15:180-4.

38. Leider AS, Jonker LA, Cook HE. Multicentric familial squamous odontogenic tumor. Oral Surg Oral Med Oral Pathol. 1989;68:175- 81 .

39. Murphy CL, Kestler DP, Foster JS, Wang S, Macy SD, Kennel SJ, Carlson ER, Hudson J, Weiss DT, Solomon A. Odontogenic ameloblast-associated protein nature of the amyloid found in calcifying epithelial odontogenic tumors and unerupted tooth follicles. Amyloid. 2008;15:89-95.

40. Solomon A, Murphy CL, Weaver K, Weiss DT, Hrncic R, Eulitz M, Donnell RL, Sletten K, Westermark G, Westermark P. Calcifying epithelial odontogenic (Pindborg) tumor-associated amyloid consists of a novel human protein. J Lab Clin Med. 2003;142:348-55. 
41. Peacock ZS, Cox D, Schmidt BL. Involvement of PTCH1 mutations in the calcifying epithelial odontogenic tumor. Oral Oncol. 2010;46:387-92.

42. Crivelini MM, Felipini RC, Miyahara GI, de Sousa SC Expression of odontogenic ameloblast-associated protein, amelotin, ameloblastin, and amelogenin in odontogenic tumors: Immunohistochemical analysis and pathogenetic considerations. J Oral Pathol Med. 2012;41:272-80.

43. Karathanasi V, Tosios KI, Nikitakis NG, Piperi E, Koutlas I, Trimis G, Sklavounou A.TGF- $\beta 1$, Smad-2/-3, Smad-1/-5/-8, and Smad-4 signaling factors are expressed in ameloblastomas, adenomatoid odontogenic tumors, and calcifying cystic odontogenic tumors: An immunohistochemical study. J Oral Pathol Med. 2013;42:415-23.

44. Harnet JC, Pedeutour F, Raybaud H, Ambrosetti D, Fabas T, Lombardi T. Immunohistological features in adenomatoid odontogenic tumor: Review of the literature and first expression and mutational analysis of $\beta$-catenin in this unusual lesion of the jaws. J Oral Maxillofac Surg. 2013;71:706-13.

45. Mosqueda-Taylor A, Carlos-Bregni R, Ramirez-Amador V, Palma-Guzman JM, Esquivel-Bonilla D, Hernandez-Rojase LA. Odontoameloblastoma. Clinico- pathologic study of three cases and critical review of the literature. Oral Oncol. 2002;38:800-5.

46. Buchner A, Kaffe I, Vered M. Clinical and radiological profile of ameloblastic fibro-odontoma: An update on an uncommon odontogenic tumor based on a critical analysis of 114 cases. Head Neck Pathol. 2013;7:54-63.

47. Buchner A, Vered M. Ameloblastic fibroma: A stage in the development of a hamartomatous odontoma ora trueneoplasm? Critical analysis of 162 previously reported cases plus 10 new cases. Oral Surg Oral Med Oral Pathol Oral Radiol. 2013;116:598606.

48. Chen Y, Li TJ, Gao Y, Yu SF. Ameloblastic fibroma and related lesions: A clinicopathologic study with reference to their nature and interrelationship. J Oral Pathol Med. 2005;34:588-95.

49. Philipsen HP, Reichart PA, Praetorius F. Mixed odontogenic tumours and odontomas. Considerations on iInterrelationship. Review of the literature and presentation of 134 new cases of odontomas. Oral Oncol. 1997;33:86-99.

50. Brown NA, Rolland D, McHugh JB, Weigelin HC, Zhao L, Lim MS, Elenitoba-Johnson KS, Betz BL. Activating FGFR2RAS-BRAF mutations in ameloblastoma. Clin Cancer Res. 2014;20:5517-26.

51. Galvão CF, Gomes CC, Diniz MG, Vargas PA, de Paula AM, Mosqueda-Taylor A, Loyola AM, Gomez RS. Loss of heterozygosity $(\mathrm{LOH})$ in tumour suppressor genes in benign and malignant mixed odontogenic tumours. J Oral Pathol Med. 2012;41:389-93.

52. Mosqueda-Taylor A, Pires FR, Aguirre- Urízar JM, CarlosBregni R, de la Piedra- Garza JM, Martínez-Conde R, MartínezMata G, Carreño-Álvarez SJ, da Silveira HM, de Barros Dias BS, de Almeida OP. Primordial odontogenic tumour Clinicopathological analysis of six cases of a previously undescribed entity. Histopathology. 2014;65:606-12.
53. Slater LJ, Eftimie LF, Herford AS. Primordial odontogenic tumor: Report of a case. J Oral Maxillofac Surg. 2016;74:547-51.

54. Buchner A, Akrish SJ, Vered M. Central dentinogenic ghost cell tumor: An update on a rare aggressive odontogenic tumor. J Oral Maxillofac Surg. 2016;74:307-14.

55. Gomes da Silva W, Ribeiro Bartholomeu dos Santos TC, Cabral MG, Azevedo RS, Pires FR; Gomes da SW. Clinicopathologic analysis and syndecan-1 and Ki-67 expression in calcifying cystic odontogenic tumors, dentinogenic ghost cell tumor, and ghost cell odontoge- nic carcinoma. Oral Surg Oral Med Oral Pathol Oral Radiol. 2014;117:626-33.

56. Sun G, Huang X, Hu Q, Yang X, Tang E. The diagnosis and treatment of dentinogenic ghost cell tumor. Int J Oral Maxillofac Surg. 2009;38:1179-83.

57. El-Mofty SK. Fibro-osseous lesions of the craniofacial skeleton: An update. Head Neck Pathol. 2014;8:432-44.

58. Dunlap CL. Odontogenic fibroma. Semin Diagn Pathol. 1999;16:293-6.

59. Allen CM, Hammond HL, Stimson PG. Central odontogenic fibroma, WHO type. A report of three cases with an unusual associated giant cell reaction. Oral Surg Oral Med Oral Pathol. 1992;73:62-6.

60. Shao Z, Liu B, Zhang W, Chen X. Synchronous occurrence of odontogenic myxoma with multiple keratocystic odontogenic tumors in nevoid basal cell carcinoma syndrome. J Craniofac Surg. 2013;24:1840-2.

61. Wright JM, Odell E, Speight PM, Takata T. Odontogenic tumors, WHO 2005: Where do we go from here? Head Neck Pathol 2014;8:373-82.

62. Shear M, Speight PM. Cysts of the oral and maxillofacial regions. 4th ed. Oxford: Blackwell Munksgaard; 2007.

63. Kramer IR, Pindborg JJ, Shear M. The WHO histological typing of odontogenic tumours. A commentary on the second edition. Cancer. 1992;70:2988-94.

64. Pavelic B, Levanat S, Crnić I, Kobler P, Anić I, Manojlović S, Sutalo J. PTCH gene altered in dentigerous cysts. J Oral Pathol Med. 2001;30:569-76.

65. Wakolbinger R, Beck-Mannagetta J. Long-term results after treatment of extensive odontogenic cysts of the jaws: A review. Clin Oral Investig. 2016;20:15-22.

66. Pogrel MA, Jordan RC. Marsupialization as a definitive treatment for the odontogenic keratocyst. J Oral Maxillofac Surg. 2004;62:651-5.

67. Martin L, Speight PM. Mini-Symposium: Pathology of the jaws. Odontogenic cysts. Diagnostic Histopathology. 2015;21:359-69.

68. Colmenero C, Patron M, Colmenero B. Odontogenic ghost cell tumours: The neoplastic form of calcifying odontogenic cyst. Craniomaxfac Surg. 1990;18:215-8.

69. Wright JM. The odontogenic keratocyst: Orthokeratinized variant. Oral Surg Oral Med Oral Pathol. 1981;51:609e18.

70. Crowley TE, Kaugars GE, Gunsolley JC. Odontogenic keratocysts: A clinical and histologic comparison of the parakeratin and orthokeratin variants. J Oral Maxillofac Surg. 1992;50:22-6. 
71. Fowler CB, Brannon RB, Kessler HP, Castle JT, Kahn MA. Glandular odontogenic cyst: Analysis of 46 cases with special emphasis on microscopic criteria for diagnosis. Head Neck Pathol. 2011;5:364-75.

72. Bishop JA, Yonescu R, Batista D, Warnock GR, Westra WH. Glandular odontogenic cysts (GOCs) lack MAML2 rearrangements: A finding to discredit the putative nature of GOC aS precursor to central mucoepidermoid carcinoma. Head Neck Pathol. 2014;8:287-90.

73. Tekkesin MS, Olgac V, Aksakalli N, Alatli C. Odontogenic and nonodontogenic cysts in Istanbul: Analysis of 5088 cases. Head Neck. 2012;34:852-5.
74. Philipsen HP, Reichart PA, Ogawa I, Suei Y, Takata T. The inflammatory paradental cyst: A critical review of 342 cases from a literature survey, including 17 new cases from the author's files. J Oral Pathol Med. 2004;33:147-55.

75. Maruyama S, Yamazaki M, Abé T, Babkair H, Cheng J, Saku T. Paradental cyst is an inclusion cyst of the junctional/ sulcular epithelium of the gingiva: Histopathologic and immunohistochemical confirmation for its pathogenesis. Oral Surg Oral Med Oral Pathol Oral Radiol. 2015;120:227-37. 